\title{
Article \\ What Is the Knowledge of Evacuation Procedures in Road Tunnels? Survey Results of Users in Poland
}

\author{
Natalia Schmidt-Polończyk ${ }^{1, *(\mathbb{D})}$, Jarosław Wąs ${ }^{2}$ (D) and Jakub Porzycki ${ }^{2}$ (D) \\ 1 Faculty of Mining and Geoengineering, AGH University of Science and Technology, al. Mickiewicza 30, \\ 30-059 Kraków, Poland \\ 2 Faculty of Electrical Engineering, Automatics, Computer Science and Biomedical Engineering, \\ AGH University of Science and Technology, al. Mickiewicza 30, 30-059 Kraków, Poland; \\ jarek@agh.edu.pl (J.W.); porzycki@agh.edu.pl (J.P.) \\ * Correspondence: nschmidt@agh.edu.pl
}

Citation: Schmidt-Polończyk, N.; Wąs, J.; Porzycki, J. What Is the Knowledge of Evacuation Procedures in Road Tunnels? Survey Results of Users in Poland. Buildings 2021, 11, 146. https://doi.org/10.3390/ buildings 11040146

Academic Editor: Francisco López Almansa

Received: 4 February 2021

Accepted: 16 March 2021

Published: 1 April 2021

Publisher's Note: MDPI stays neutral with regard to jurisdictional claims in published maps and institutional affiliations.

Copyright: (c) 2021 by the authors. Licensee MDPI, Basel, Switzerland. This article is an open access article distributed under the terms and conditions of the Creative Commons Attribution (CC BY) license (https:// creativecommons.org/licenses/by/ $4.0 /)$.

\begin{abstract}
This paper presents a preliminary assessment of road tunnel safety issues among respondents - specifically, real and potential users of road tunnels. We recruited a group of respondents to study their knowledge of evacuation procedures and awareness of safety issues in road tunnels. We conducted surveys with 504 participants, $12.7 \%$ of whom had previously participated in realscale evacuation experiments in a road tunnel. Analysis of respondents' answers reveals that their knowledge of safety procedures is unfortunately not sufficient. On average, the respondents selected the most recommended answer for approximately 5.35 out of 15 questions. Only $16 \%$ of respondents correctly answered more than $50 \%$ of the survey questions; moreover, no respondent provided the correct answers for 12 or more questions. Interestingly, most respondents were convinced that they had a better knowledge of road tunnel safety issues than was actually the case. The results of the survey demonstrate a significant educational role of evacuation exercises. Individuals who have participated in an evacuation have better knowledge, allowing them to apply the correct rules of road tunnel safety procedures. Various aspects addressed in this paper can be taken into consideration in an information campaign regarding safety in road tunnels during a fire.
\end{abstract}

Keywords: road tunnel fire; safety; evacuation; survey; education; evacuee's behavior during fire

\section{Introduction}

Road tunnels constitute an important element of road infrastructure. Due to their specific construction (consisting of a partially confined space) one can identify a number of risks associated with the use of tunnels. Although, from a statistical point of view, the accident rate is lower than that for open-air roads, it is worth noting that, due to the geometric characteristics of road tunnels, the risks associated with them are significantly different in terms of scale when compared to open road spaces [1]. It should be highlighted that the consequences of accidents in partially enclosed spaces, such as tunnels, can be much more severe [2].

The level of education of road users is an important factor influencing the accident rate [3]. This is also the case with road tunnels, as proven by the tragic consequences of tunnel fires, e.g., in the Mont Blanc tunnel in 1999, where people involved in the situation did not evacuate immediately due to being oblivious to the threat and safety procedures [4]. In recent years, many such accidents have been reported, for instance, the fire in Taojiakuang Tunnel in Weihai in China, 2017 (12 fatalities); the fire in Yanhou tunnel in China that occurred in 2014 and resulted in 40 fatalities; the fire in Eiksund tunnel in Norway in 2009 (five fatalities); and the fire in Viamala tunnel in Switzerland in 2006, which resulted in nine fatalities.

There is potential for improving the safety of road tunnel users. There are many methods to do this, such as the improvement of technical infrastructure [5-7], tunnel 
equipment [8-10], and safety procedures [11-13], and training of the personnel responsible for safety in tunnels and rescue services training [14]. All of these systems are important to ensure safety in road tunnels. However, it is not possible to exclude the human factor.

To improve safety in road tunnels, Directive 2004/54/EC emphasizes the role of information campaigns that should encompass correct behavior of road users when approaching and passing through tunnels, especially due to vehicle failure, congestion, accidents, and fires. This is, however, associated with raising the level of safety education. The strategy for educational measures should be based on an analysis of the level of knowledge of potential road tunnel users. All policies in this regard should be comprehensive and, importantly, rely solely on proven hypotheses $[15,16]$. Reporting on the results of the assessment of awareness among road tunnel users should be the first step towards improving their education, including their behavior and knowledge of the safe use of the structures in question [17].

The intention of the authors was to perform a preliminary assessment of road tunnel safety issues among respondents, specifically, real and potential users of road tunnels. In central-eastern Europe, a dynamic increase in the number of tunnels is planned in the coming years; for instance, in Poland the number of road tunnels will double in the next three years (and further additional investments are under preparation). The developed methodology, which applied the surveying technique, included questions verifying the knowledge of the rules of safety procedures in Polish road tunnels (on the basis of the above-mentioned directive of the European Union [14] and safety instructions in road tunnels in Poland $[18,19])$. The analytic instrument used to assess knowledge of evacuation procedures and awareness of safety issues of potential tunnel infrastructure users identified the relevant variables to formulate a preliminary assessment of the situation among drivers. This was the first attempt at a broader diagnosis of the users' knowledge of safety procedures in road tunnels in Poland. We suppose that individuals do not have sufficient knowledge about safety procedures. Simultaneously, we expect that individuals are not aware of some possible, unfavorable scenarios, and there may be difficulties with self-assessing their knowledge of road tunnel safety procedures. We suppose that the respondents who participated in earlier evacuation exercises have experience that affects the proper threat assessment and knowledge of evacuation procedures.

The article is organized as follows. Section 2 presents related works, and Section 3 includes the research methodology, survey outline and parts, participant profiles, and comparison with the results of experiments. The results from the survey are presented in Section 4 and in Appendix B. Discussions are presented in Section 5, which include the analysis of: familiarity with the tunnel infrastructure, behavior in the event of a traffic jam, selecting the evacuation route, behavior during evacuation, personal belongings during evacuation, self-evaluation of road tunnel safety knowledge, and the role of experience. Finally, Section 6 includes a summary of the results and concludes the research. The entire survey with comments is presented in Appendix A.

\section{Related Works}

Various methodologies are used in road tunnel safety studies. These include research based on real-case analyses, experimental studies, surveys, and computer simulation studies. It should be stressed that the behavioral aspects of an evacuation process have become an increasingly more important subject of research in recent years $[3,17,20-25]$. Surveying has been employed by various researchers to investigate evacuation safety. For example, Lovreglio et al. [22] proposed a three-stage methodology covering the following stages: preliminary analysis, qualitative analysis, and modelling and behavioral analysis. The qualitative analysis stage concerned online surveys involving 14 groups of respondents. The questions related to, among other things, the strategy of making decisions about the direction of evacuation, including avoiding congested areas to evacuate more quickly, and selecting congested exists to avoid evacuating alone. In contrast to our approach, the 
authors used online surveys. Conversely, the research also took into account the user's perspective, as applied in our work.

In the context of assessing the awareness of safety issues in road tunnels, an online surveying method was used in [21]. That paper presents the results of a survey involving 1129 drivers in Greece, and examining their knowledge of tunnel safety rules, with a view to developing the most effective information strategies on tunnel safety. In that work the authors confirmed that their respondents had several misconceptions regarding the most recommended behavior for normal conditions and for dangerous situations. For instance, $60 \%$ of respondents stated that when they saw traffic lights before the tunnel turning from green to red they would "reduce speed and continue driving through the tunnel" [21]. Another example was a question about their reaction to smoke coming out from the bonnet of their vehicle while driving through a road tunnel. The authors confirmed that only $38.7 \%$ of respondents described the recommended behavior, which is to continue driving, if possible, and then leave the tunnel. In our work, we also use an evaluation of the answers, indicating the most recommended actions.

Casse and Caroly [26] presented an analysis of critical incidents reported by tunnel safety professionals. In their face-to-face interviews, they identified 93 critical situations. A series of vertical evacuation experiments was carried out by Xie et al. [27] in an underwater shield tunnel to estimate evacuation times. One of the most important decisions of an evacuee is choosing an appropriate exit. This issue was investigated in [23]. Ronchi et al. conducted an evacuation experiment in a road tunnel in Stockholm, and found that adding information signs, signposts, and speakers at the exit might improve the likelihood of people's finding and using emergency exits in tunnels.

Developing tunnel-evacuation procedures was the subject of research conducted in the Sydney Harbour Tunnel [8]. That study involved the evacuation of 32 volunteers from a controlled "burning car" scenario. The findings from that work indicate that early, loud-andclear, audio messaging can expedite early decisions to evacuate. Fridolf et al. [28] analyzed correlations between walking speed and visibility coefficients measured in real tunnels. On the basis of their broad analysis, they identified several equations for various categories of evacuated users, as well as for different situations. In their paper, Kouabenan et al. [29] studied the responses of tunnel users to various road tunnel fire scenarios. A group of 217 individuals, students at a French university, were asked to describe their reactions to various fire scenarios, taking into account their stress levels. The methodology of that psychological research included a survey and predicted actions. The study demonstrated, i.a., that smooth traffic flow made drivers more likely to engage in risky (U-turns) and nervous (sounding the horn) behavior, as compared to in congestion or traffic jams. The use of virtual reality in surveys among tunnel users was presented in two papers by Kinateder et al. [20,30]. Particularly noteworthy is their comparison of the reactions to dangerous situations in a real road tunnel, between people trained with Virtual Reality (VR) applications and those who were given only general instructions.

\section{Research Methodology}

The aim of this paper is to focus on another relevant aspect of evacuation safety studies; namely, the use of surveys to assess road tunnel safety. The surveys involved 504 participants, of whom $12.7 \%$ had previously participated in experimental studies on road tunnel evacuation [17]. This paper corresponds to projects including experimental research in the field of road tunnel evacuation [17], correlation analysis of one-way-traffic speed [31], and the use of effective evacuation simulation methods [32].

\subsection{Survey Outline}

The surveying method was employed to assess the knowledge of evacuation procedures and awareness of safety issues in road tunnels in normal use and emergency situations. The questionnaire includes a number of questions designed to verify whether respondents know the principles of safe tunnel use, are able to correctly evaluate various 
emergency situations, and are aware of tunnel risks, as well as to identify any gaps in their knowledge and to assess behavioral factors in various situations. The survey was prepared on the basis of previous similar studies [8,20,21,29,33-37]. The present survey incorporates safety instructions for road tunnels in Poland $[18,19]$, but it concerns general safety recommendations and rules. Before the questionnaire was filled out by all respondents, it was verified in small randomized groups. Next, the questions were adjusted to account for any reported misinterpretations. One of the procedures used for testing and preparing these questionnaires was to discuss the sample results with tunnel management personnel and safety officers. Another procedure was to have questions and hypotheses verified by professional statisticians.

\subsection{Survey Parts}

The survey is composed of four parts. Part one includes census data: age, gender, education, occupation/study program, place of residence and how long the respondent has had a driving license. Part two asks questions concerning the use of road tunnels by the respondents and their knowledge of the rules for safe use of tunnels and evacuation. Part three, which was the main part of the survey, included multiple choice questions to verify the knowledge of safety procedures in tunnels in various situations (according to Polish and European regulations), as well as awareness of safety issues. Part four was about evaluating the situation inside the tunnel and respondents' potential reactions to certain scenarios. Respondents were asked to choose the behavior they would probably adopt from a list of proposed actions by selecting one of the possible answers, or providing their own. In order to evaluate the overall knowledge of respondents (the total score), we identified two types of answer-he most recommended answers (according to Polish safety instructions) and other answers. The entire survey, with comments, is presented in Appendix A.

\subsection{Participant Profile}

The survey involved 504 participants. Respondents were recruited as potential users of road tunnels. We recruited a group which was diverse in terms of age, place of residence, period of holing a driver's license, frequency of using road tunnels, etc. In addition, we took into account a range of levels of evacuation experience. The surveys were conducted in different cities across Poland in which road tunnels were located. The respondents answered the questions anonymously, and had given their prior consent to participate in the survey. Before receiving the questionnaire, the participants had been informed about the purpose and form of the questionnaire. The survey was conducted in closed, silence rooms. The respondents filled the paper version of survey. The completion time was approximately $15 \mathrm{~min}$. Among the respondents 56.5\% were men and 43.5\% were women. The age of the respondents ranged from 13 to $69(\mathrm{Me}=26, \mathrm{M}=29.83, \mathrm{SD}=10.61)$, and the majority of them $(49.2 \%)$ were between 19 and 24 , while the rest were $13-18$ years old $(4 \%)$, 25-34 years old (20.6\%), 35-50 years old $(19.8 \%)$, or $51-69$ years old $(6 \%)$. We found that $53.4 \%$ had higher education, $40.7 \%$ had secondary education, and the remaining respondents had primary, lower-secondary or vocational education. The respondents were also asked to specify their place of residence: $32.3 \%$ resided in rural areas, $16.1 \%$ in cities with populations of up to $50,000,8.7 \%$ in cities with populations of 50,000 to $100,000,17.7 \%$ in cities with populations of 100,000 to 500,000 , and $25.2 \%$ in cities with populations of more than 500,000 . The vast majority of the respondents $(89.4 \%)$ had driving licenses, and more than $73.7 \%$ of them had had a driving license for more than four years. We decided not to exclude persons who did not have a driving license as passengers are also potential users of tunnels. The participants' profile characteristics are provided in Table 1. 
Table 1. Participants' profile characteristics.

\begin{tabular}{ccc}
\hline Gender & Female & Male \\
& $43.5 \%$ & $56.5 \%$ \\
\hline \multirow{2}{*}{ Age } & $\mathrm{M}$ & $\mathrm{SD}$ \\
& 29.83 & 10.61 \\
\hline \multirow{2}{*}{ Education } & Higher & Secondary \\
& $53.4 \%$ & 40.7 \\
\hline \multirow{2}{*}{ Place of residence } & Populations $>500,000$ & Populations of 100,000 to 500,000 \\
& $25.5 \%$ & $17.7 \%$ \\
\hline \multirow{2}{*}{ Driving license } & Yes & No \\
& $89.4 \%$ & $10.7 \%$ \\
\hline \multirow{2}{*}{ Driving experience } & $\mathrm{M}$ & $\mathrm{SD}$ \\
& 10.71 & 9.03 \\
\hline
\end{tabular}

This group should know how to behave in tunnels at least as well as drivers. The results showed that $14.5 \%$ of the respondents did not use road tunnels, $40 \%$ used them once or several times a year, $19 \%$ several times a year, and $26.4 \%$ several dozen times a year or more. The results showed that $23.4 \%$ of the respondents used road tunnel infrastructure with a length of $500-1000 \mathrm{~m}$ and $29.1 \%$ of the respondents used tunnels with a length exceeding $1000 \mathrm{~m}$, with $8.7 \%$ of them using tunnels longer than $3000 \mathrm{~m}$.

\subsection{Comparison with the Results of Experiments}

In order to better evaluate the survey results, partial results were compared with observations from real-scale experimental studies on evacuation, conducted by us in the Emilia tunnel in Laliki, Poland [17] and in the tunnel under the Martwa Wisła River in Gdańsk. Approximately 50 students of the AGH University of Science and Technology took part in the first experiment in the Emilia tunnel in Laliki in 2016. The evacuation studies consisted of four tests simulating a vehicle collision resulting in a fire inside the tunnel. The other evacuation experiment, consisting of three tests, was performed in June 2017 in the tunnel under the Martwa Wisła River in Gdańsk, the longest road tunnel in Poland. The experiment involved 90 participants of different ages. Both evacuation experiments were conducted using nontoxic cold smoke to create experimental conditions which would reflect as accurately as possible the conditions during a fire, the greatest threat associated with tunnel use. In order to ensure the safety of the participants, the experiments were conducted with the assistance of the fire service, the police and medical services. The tunnels were closed to vehicle traffic for the duration of the tests. The flow of evacuated people as well as experiment participants' behavior was observed using cameras located in front of the coach in the road tunnel, inside the vehicle, at cross passages leading to the evacuation tunnel or to the second tunnel tube, in the evacuation tunnel itself or in the second tube of the tunnel, in front of tunnel portals, and also in other locations. Furthermore, due to very poor visibility near the coach, thermal imaging cameras were used to observe the behavior of the evacuees. In order to precisely measure the evacuation time [28] of every individual, the organizers used the Chronotrack measurement technology.

\section{Survey Results}

We found that $16 \%$ of respondents answered more than $50 \%$ of the survey questions by selecting the most recommended answers (a sum for parts 3 and 4). The most recommended answers for more than 10 questions were given by $3 \%$ of respondents, and no one pointed out the most recommended answers for 12 or more questions (see Figure 1). On average, the respondents properly (optimally) selected the answers to 5.35 out of 15 questions $(\mathrm{Me}=5, \mathrm{M}=5.35, \mathrm{SD}=2.13)$ found in both parts of the survey. 


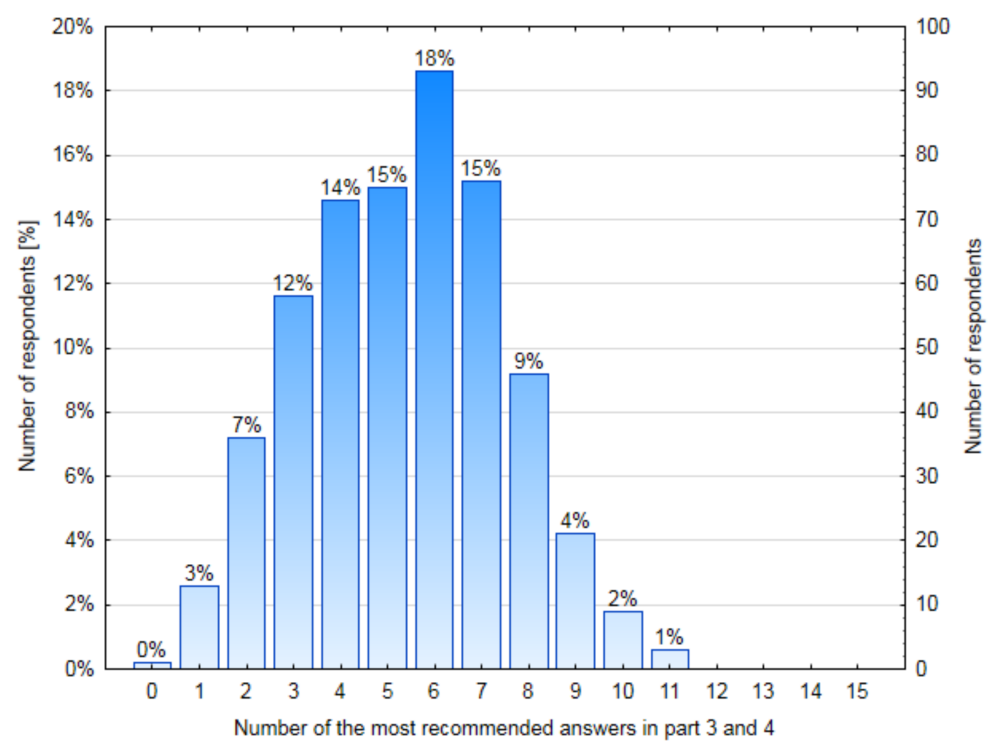

Figure 1. Overall survey results—histogram of number of the most recommended answers.

The knowledge of road tunnel safety procedures was examined by analyzing the answers to the questions in part 3 of the questionnaire. None of the respondents pointed out the most recommended answers to more than 9 questions, and only 1 respondent pointed out 9 answers to a total of 12 questions. On the other hand, $1.2 \%$ of the respondents pointed out only the most unrecommended answers to all questions. The highest number of respondents $(22.6 \%)$ selected the most recommended answers for 4 out a total of 12 questions ( $\mathrm{Me}=4, \mathrm{M}=3.55, \mathrm{SD}=1.65)$. The number of the correct answers to the questions in part 3 of the survey is presented in Figure 2.

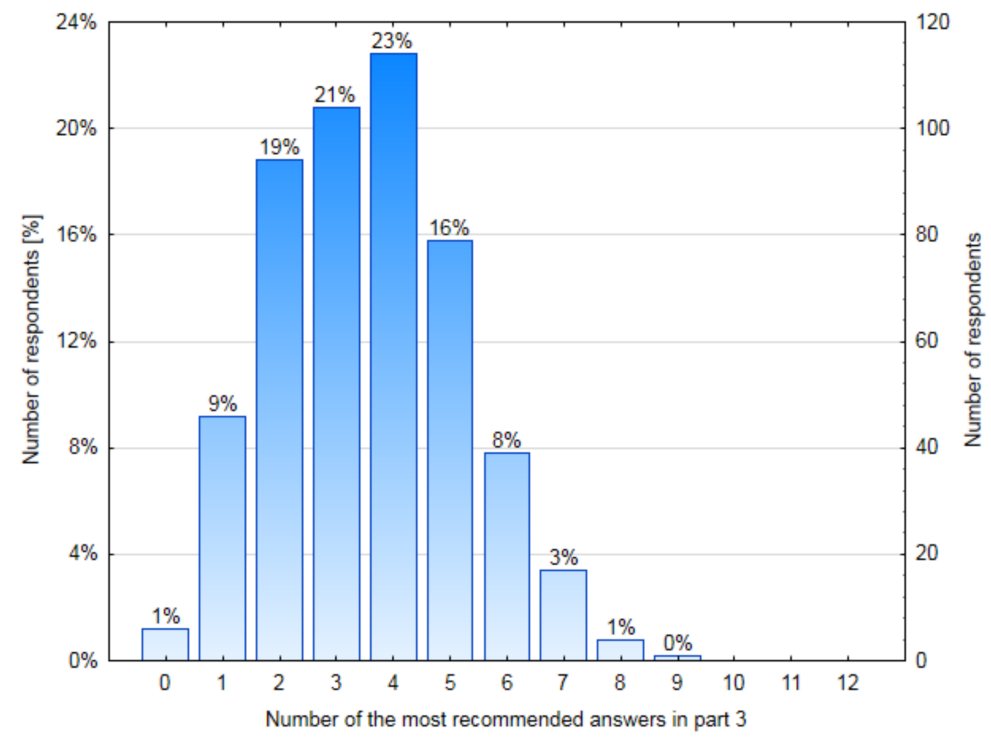

Figure 2. The number of the most recommended answers to questions in part 3 of the survey.

The respondents' reactions to scenarios and ability to correctly assess road tunnel threats were evaluated by examining the results of part 4 of the survey, in which the respondents were asked to give one answer to each of the three questions describing a road tunnel emergency. We calculated the sum of all the most recommended answers given by each respondent. Only $9 \%$ of respondents gave any of the most recommended answers, $27 \%$ provided only one, and $39 \%$ two of the most recommended answers. Only $25 \%$ of 
survey participants correctly assessed all tunnel emergency situations and selected the most recommended answers $(\mathrm{Me}=2, \mathrm{M}=1.8, \mathrm{SD}=0.92)$ (Figure 3 ). We also analyzed the answers to each question in both parts of the survey-the results and figures for each questions are presented in Appendix B.

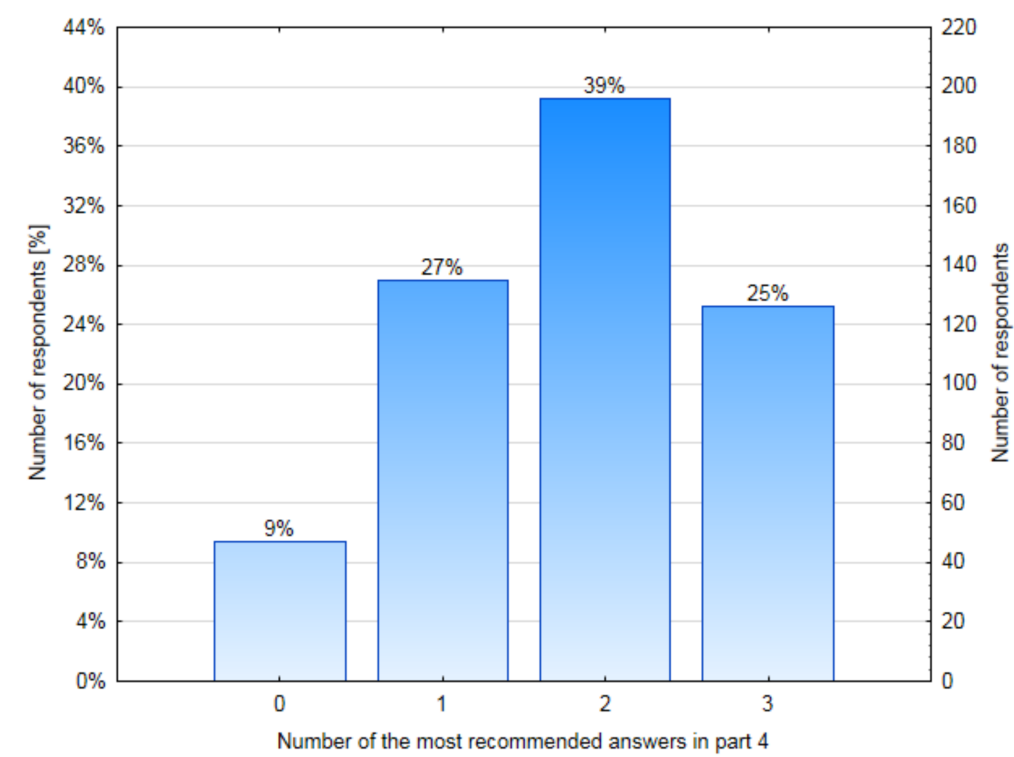

Figure 3. The number of the most recommended answers in part 4 of the survey.

\section{Discussion}

Based on the results of the survey, the authors confirmed the first research hypothesis:

Hypothesis 1 (H1). The majority of the surveyed individuals do not have sufficient knowledge about safety procedures.

The survey results are the direct proof of the validity of Hypothesis 1, as none of the respondents selected the most recommended for all of the questions. Only $16 \%$ of the respondents pointed out the most recommended answers for more than 7 questions to a total of 15 questions. No one selected the most recommended answers for more than 11 questions-Figure 1.

The respondents' answers constituted nothing more than responses to the fire scenarios described in the survey, resulting from their assessment of the threat level. None of the respondents gave the most recommended answers to all 12 questions in part 3 of the survey, concerning tunnel safety procedures. Only one respondent gave nine of the most recommended answers, and most survey participants $(22.6 \%)$ gave the most recommended answer to only four questions-Figure 2. The specific answers to some questions in the survey appear interesting.

\subsection{Familiarity with the Tunnel Infrastructure}

Some of the respondents were unfamiliar with the tunnel infrastructure, as demonstrated in question 1 in part 3 of the survey. We found that $14.5 \%$ of the respondents expected a cycling path, and $4.2 \%$ a car park, in the tunnel-Figure A1a, Appendix B. In tunnels, it is prohibited to ride bicycles and to stop the vehicle without a legitimate reason. We also found that $18.9 \%$ of the respondents were convinced that it was prohibited to use the horn or hazard warning lights while driving in a tunnel (1.8\%)-question 2, part 3 -Figure A1b, Appendix B. It is also alarming that 5.6\% of the respondents would turn off the radio before entering the tunnel, which is used by the management center to make voice announcements on a dedicated frequency-question 3, part 3-Figure A1c, Appendix B. 


\subsection{Behavior in the Event of a Traffic Jam}

Emergencies in road tunnels include tailbacks, which should be avoided whenever possible by means of appropriate traffic control in the tunnel. However, since such situations do happen in road tunnels, users should be aware of the applicable safety rules. In the event of a tailback in a road tunnel (question 8, part 3), only $30.7 \%$ of the respondents would turn on the hazard warning lights-Figure A2b, Appendix B. This is very important to ensure safety. There have been cases in which failure to adhere to several basic rules for tailback situations in road tunnels (exceeding the speed limit, not maintaining safe distances between the vehicles and not turning on the hazard warning lights) caused accidents [22]. Only a small percentage of the respondents $(6.0 \%)$ would turn on their radios, which may stem from their being oblivious to the possibility of receiving information about tunnel traffic or threats via a radio tuned to a dedicated frequency (information about the frequency is available on information boards before the tunnel entrance). We found that $44.2 \%$ of the respondents would stop the vehicle and turn off the engine. This is also important, since it reduces the level of harmful solids and gases emitted by vehicles in the confined space of the tunnel. Only three respondents answered this question correctly, which can stem from incomplete knowledge and unfamiliarity with tunnel infrastructure.

\subsection{Stopping Inside a Tunnel}

Despite the source of danger being behind the vehicle (question 2, part 4), 37.1\% of the respondents would stop their vehicle in the event of a tunnel fire-Figure A3b, Appendix B. Stopping inside a tunnel without a legitimate reason can pose an additional risk and result in a situation endangering other users or end in a tragedy. The intention of stopping the car, as indicated by $37.1 \%$ of the respondents, proves their lack of awareness of the possible danger, and demonstrates their misjudgment of the situation.

It is difficult to assess how the respondents would have behaved when faced with real danger, but such a high percentage of incorrect answers clearly points to their lack of knowledge.

\subsection{Selecting the Evacuation Route}

In question 1, part 4 of the survey, $29 \%$ of the respondents would go to the nearest emergency exit, which can actually put the evacuees at risk-Figure A3a, Appendix B. If the nearest emergency exit leads towards the fire (as in the scenario described in question 1 ), the evacuees should go in the direction opposite to the source of the fire, avoiding the smoke.

In question 3 (part 4), the answer in which the emergency exit was leading towards the fire was selected by only $3 \%$ of the respondents (in the first question by as many as $29 \%$ ) Figure A3c, Appendix B, perhaps because the answers to question 3 were formulated more directly. The expressions used were towards the fire and opposite to the source of the fire, and no distance to the exits was specified. Maybe the respondents paid attention to the direction of evacuation when answering this type of question for the second time-and this was the effect of learning. However, when analyzing the answers to question 11 in part 3 of the survey, in which the respondents were asked what should be done in the event of a collision and vehicles being on fire in front of them, with substantial smoke accumulation in the road tunnel and the fire alarm's being triggered, $43.4 \%$ of the respondents opted for going to the nearest emergency exit-Figure A2e, Appendix B-forgetting about an important evacuation rule- "avoid the smoke".

We would like to draw the reader's attention to the information found in road tunnel safety instructions. In some instructions, we found terminological imprecision. For instance-If the vehicle in front of you is on fire, you have to turn off the engine and immediately leave the tunnel by the nearest emergency exit. A message formulated in such a way, indicating no need to avoid the smoke or to move in the direction opposite to the source of the fire, may mislead the potential user. 
One interesting issue related to road tunnel fires is the decision-making process and the choice of the evacuation route. Going back to question 11, part 3 of the survey: In the event of a collision and vehicles being on fire in front of you and substantial smoke accumulation in the road tunnel, and the fire alarm being triggered ... two out of the three most frequent answers concerned the process of selecting the direction/route of evacuation. The answers given by the respondents were compared with the results of the real-scale evacuation experiment in the Emilia tunnel in Laliki [17]. In the case of the selection of the evacuation route, we focused on experiments 1 and 4. During experiment 1, the participants did not know what would happen, so the experiment was considered to be the closest to real-life situations. In experiment 4, the vehicle stop location was changed; therefore, in this case the analyzed issue was the choice of the evacuation route under difficult conditions of very poor visibility. The most recommended answer selected by most respondents: (a) go to the emergency exit, avoiding the smoke $(71.1 \%)$ was reflected in the behavior of experiment 1 participants, where there was a small amount of smoke in the tunnel. At first, the participants did not know what to do. They left the vehicle and stood in front of the bus door, looking around. The decision on the selection of the evacuation route was made as a result of a discussion after another group of five students joined in. Then, the evacuation route was selected in line with the tunnel evacuation signs and in such a manner as to avoid smoke. The participants intentionally headed towards an exit opposite to the source of the fire. The selection of the evacuation route in experiment 1 is presented in Figure 4. This behavior changed in experiment 4, however, and the participants, even though it was fourth experiment they took part, behaved similarly to the group of $43.4 \%$ of the survey respondents who selected another answer (not the most recommended): (b) go to the nearest emergency exit. It is worth highlighting that during experiment 4, the positioning of the coach in the tunnel was changed (it was parked in a different lane, but in the same direction, approximately $120 \mathrm{~m}$ farther down the tunnel), and the participants had their eyes covered when the vehicle entered the tunnel, which prevented them from using the acquired knowledge and selecting the same evacuation route. Furthermore, the accumulation of smoke in the tunnel was significantly larger during the last experiment; thus, the observation of the participants' behavior was only possible using a thermal imaging camera.

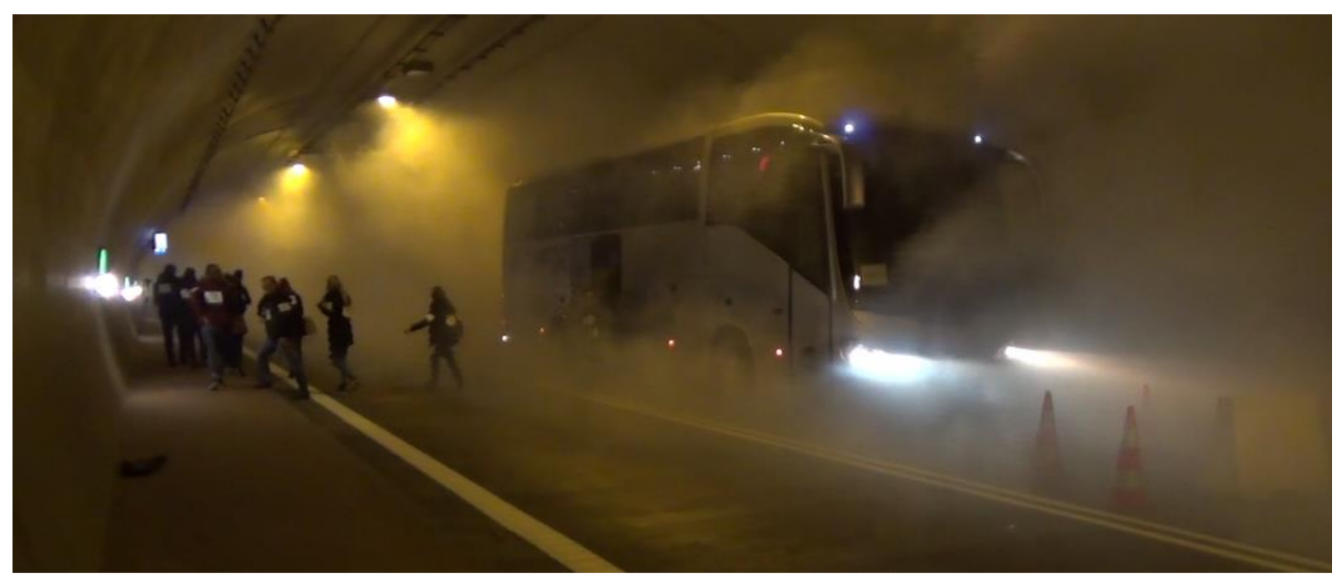

Figure 4. The selection of the evacuation route during experiment 1 in the Emilia tunnel in Laliki.

Due to poor visibility, after leaving the vehicle, the participants formed organized groups. Each person probably saw only the person in front of him/her and followed that person. These self-organized groups left the tunnel heading towards the smoke, by selecting the nearest emergency exit, i.e., towards the source of the fire. The fact that participants in experiment 4 opted for the shortest evacuation route may be due to their losing their sense of direction as a result of the substantial accumulation of smoke. 


\subsection{Behavior during Evacuation}

A misjudgment of the situation was also noted when analyzing the other answers to question 11, since option $\mathrm{f}$ - use the emergency cabinet to call for help-was selected by as many as $66.5 \%$ of the respondents. The scenario described in that question clearly indicates that the situation inside the tunnel is critical, and the only reasonable action is immediate evacuation. Ultimately, as many as $85.1 \%$ of the respondents answered question 11 incorrectly, which was probably due to their lack awareness of the consequences of road tunnel threats, as well as knowledge of procedures of evacuation.

It is noteworthy that in a fire situation (question 3, part 4), $14.2 \%$ of the respondents would run to leave the area as quickly as possible, heading to the emergency exit in a direction opposite to the fire. Any attempt to run in low visibility conditions can pose a risk to human health or life. In every tunnel, there is a curb that separates the evacuation route from the road lanes to prevent drivers from entering the pedestrian area in the event of an emergency. Tunnels very often lack additional curb markings, which is why running during the evacuation under low visibility conditions can result in a fall. This was observed during the evacuation experiment in the Emilia tunnel in Laliki in the situation of substantial smoke accumulation. Due to very poor visibility, the curb became a serious obstacle during the evacuation. Several participants tripped on the curb (Figure 5) and some ran into one another. The experiment participants who did not trip on the curb moved slower and more carefully, but stated that they had not seen the curb when the accumulation of smoke was heavy. Therefore, running while evacuating under conditions of poor visibility may lead to dangerous situations, endangering the health and even life of evacuees.
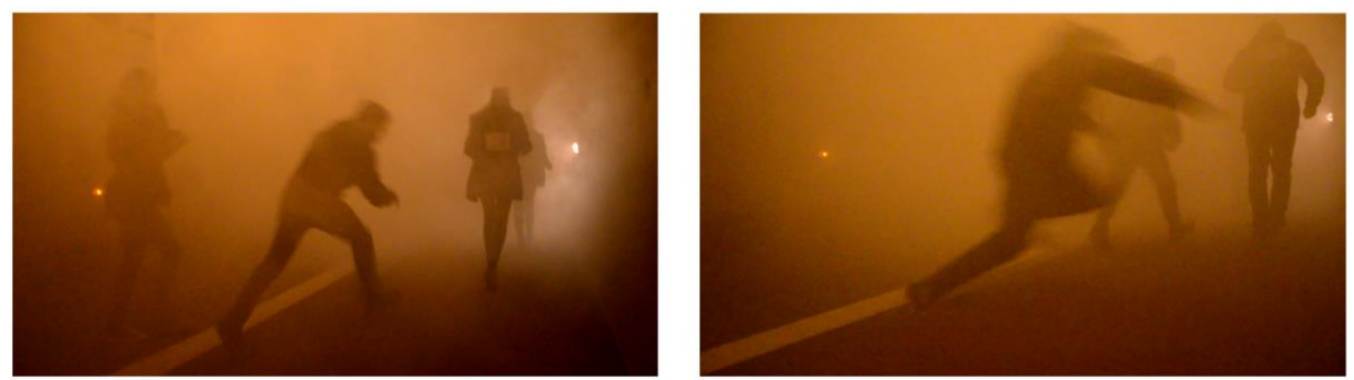

Figure 5. Two examples of participants tripping on the curb and falling during the road tunnel evacuation experiment.

In question 3, part 4 of the survey, the most recommended answer-move as close to the ground as possible, and head to the emergency exit in the direction opposite to the fire-was selected by $71.9 \%$ of the respondents. However, during experiment 4 of the evacuation research, where the accumulation of smoke was the heaviest, none of the participants moved close to the ground. It should be emphasized that before this test, the participants in the evacuation experiment received tunnel safety instructions with the following information: in the event of dense smoke, move up close to the ground. Nevertheless, no one followed these guidelines. Therefore, the evaluated answers to question 3 , part 4 of the survey, were only those given by the experiment participants. Encouragingly, $81.5 \%$ of them gave the correct answer. This can indicate that the respondents, including the participants in the experiment, had theoretical knowledge of how to act in this particular situation, but their ability to apply this knowledge in fire conditions (limited visibility, emergency systems in operation) seems questionable.

\subsection{Familiarity with the Tunnel Safety Systems}

The respondents satisfactorily indicated the systems that are triggered in the event of a tunnel road fire-question 10, part 3: the fire alarm $(89.8 \%)$, voice announcements informing about the fire and the necessity of leaving the tunnel (85.2\%), and emergency lights (73.1\%)-Figure A2d, Appendix B. However, as many as $69 \%$ of them could not name all 
the systems which could be triggered in the event of a fire. These three systems, which the respondents were most likely to indicate, inform users inside the tunnel about the danger (fire), as well as initiate and facilitate immediate and safe evacuation. After the systems are triggered, the persons in the tunnel should proceed to self-rescue. Unfortunately, this is not always the case, as shown by the results of the real-scale experiment in the Emilia road tunnel in Laliki [17].

The first test of the evacuation experiment, in which the participants did not know the purpose or scenario of the test, and were unfamiliar with the tunnel infrastructure, examined their reaction to the tunnel infrastructure in fire conditions. It should be underlined that before entering the tunnel, the participants did not know that the evacuation experiment would involve smoke in the tunnel.

After the vehicle stopped, the students remained in their seats. Their behavior remained the same after noticing smoke in the tunnel and they made no attempts to leave the coach, but only discussed the situation. It was noted, however, that after the smoke appeared in the tunnel, some of the participants appeared worried, and even a little nervous. Once the alarm was sounded, the students remained in their seats (one person checked the possibility of making a phone call in the tunnel). The voice announcement during the fire procedure probably "encouraged" the first experiment participants to leave the vehicle, but this was observed only after about half a minute. One participant said that such an announcement would not have been made during a real evacuation, which was particularly interesting.

An appropriate and quick response to the "what to do" systems in the tunnel can significantly facilitate the evacuation process and eliminate the delay in making the evacuation decision, as is often the case. It is also puzzling that (in question 10) only half the respondents (49.5\%) indicated ventilation as a system which is turned on during a fire. In tunnels, the ventilation system plays the very important role of extracting fire gases and fumes to make safe evacuation possible.

Furthermore, it is important to acknowledge the differences between the answers given by participants in one of the two evacuation experiments described in point 3.4 and those given by the other survey respondents (without such experience). It seems that the individuals who had already experienced a road tunnel evacuation (by participating in an evacuation experiment) were more familiar with a tunnel's fire infrastructure. This is confirmed by the answers, where $98.5 \%$ of the evacuation participants named the fire alarm and voice announcements, and $90.8 \%$ the emergency lights, as systems which would be triggered during a tunnel fire-Figure 6. On average, this result was $13.2 \%$ better than in the case of individuals with no such experience.

It is worth noting that the ventilation system was indicated by similar percentages of respondents in both analyzed groups. Such a poor result among the experiment participants (only 50.8\% selected answer e: ventilation) probably stems from the fact that the system was not activated during the experiment. More information on the comparison of the results of the survey obtained by the evacuation experiment participants, other individuals with experience in any evacuation, and the other respondents is presented in Section 6. 


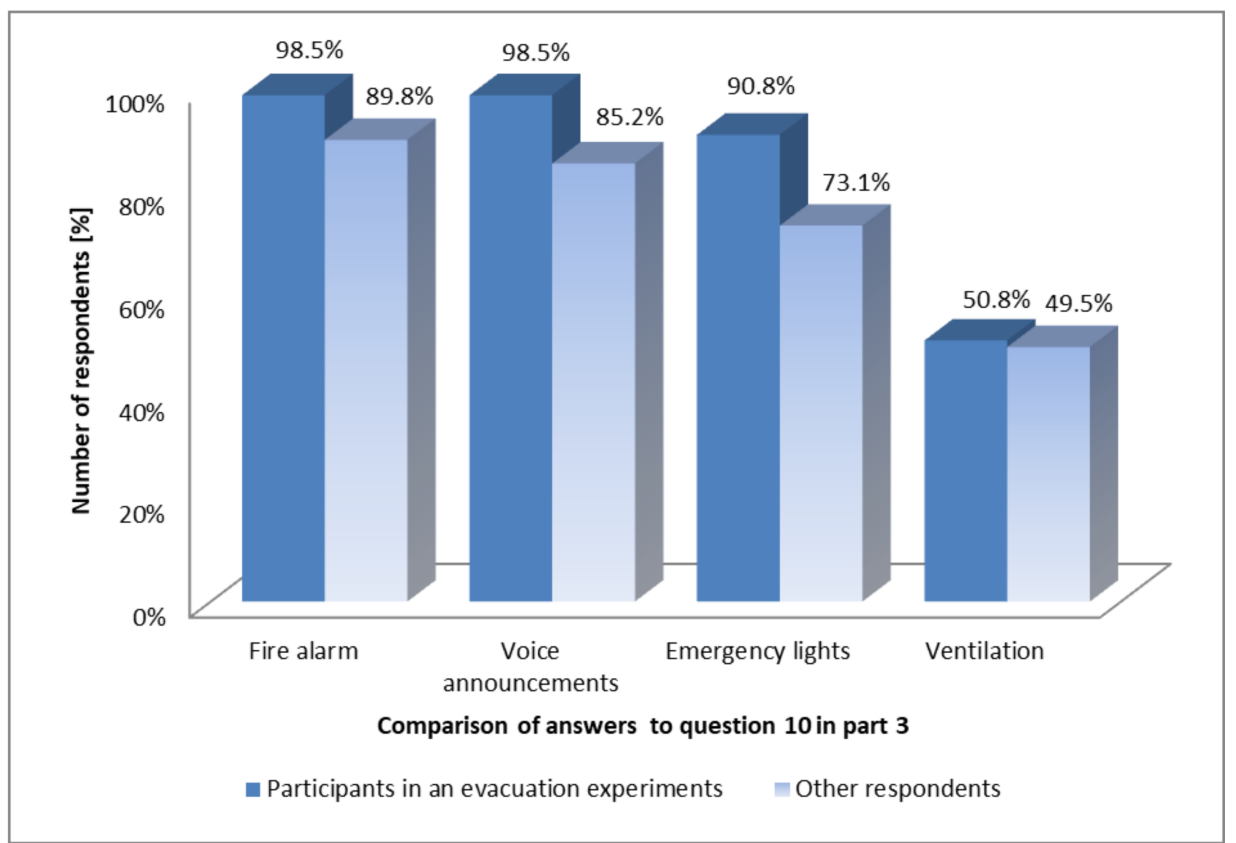

Figure 6. Answers given by the evacuation experiment's participants and other respondents to the question about the systems which can be activated during a fire in a road tunnel.

\subsection{Personal Belongings during Evacuation}

It is also important to examine the answers given to question 7 in part 3 of the survey: What do you take with you if you suddenly have to leave your car in the tunnel? It was assumed that the respondents knew when it was necessary to leave the car in the tunnel (question 5, part 3), i.e., always, in the event of a tunnel fire if there is no option to drive out of the tunnel ( $86.3 \%$ of the answers)-Figure A1e, Appendix B. The vast majority of the respondents $(68.1 \%)$ would take documents, $38.7 \%$ a first-aid kit, $37.1 \%$ a fire extinguisher, $34.7 \%$ water, $21.8 \%$ car keys, $14.7 \%$ most valuable items, and $1.8 \%$ as much as they could carry. Only $17.3 \%$ of the respondents selected the most recommended answer: none of the answers is correct, but only $16.3 \%$ opted for this answer only, thereby correctly answering the question-Figure A2a, Appendix B.

The time needed to find and take the intended item is likely to extend the time needed to start evacuation, which in critical conditions, and those can occur immediately during a fire, can make all the difference to this person's health or even life [38]. There have been many cases in which people lost their lives in a road tunnel fire because they delayed their evacuation (a substantial number of people stayed in their vehicles instead of starting evacuation immediately) or lost valuable time to salvage their belongings. A large percentage of the victims of the fires in the Mont Blanc, Tauern and Gotthard tunnels were found dead in their vehicles or right next to them [4].

In addition, it is worth noting the answers concerning vehicle keys (question 7, answer d, part 3). As many as $21.8 \%$ of the respondents would take the keys, while during a tunnel fire, it is recommended that the keys should be left in the ignition to facilitate rescue (mainly firefighting) operations for the relevant services, enabling them to move the vehicle if it blocks the path to the source of the fire. This aspect was also analyzed in question 12: If it is necessary to leave the car in a road tunnel due to a vehicle in front of you being on fire, you should: where $56.0 \%$ were correct answers- i.e., leave the car open and the key in the ignition-and $44.0 \%$ were incorrect answers, with $33.9 \%$ indicating that one should take the keys.

\subsection{Self-Evaluation of Road Tunnel Safety Knowledge}

The respondents' self-evaluation of their knowledge of road tunnel safety procedures also provided interesting insights. We tested the second research hypothesis: 
Hypothesis 2 (H2). The majority of respondents consider their knowledge of road tunnel safety procedures to be better than it actually is.

Question 3, part 2-Do you know the rules of safe road tunnel use?-was answered as follows: $14.7 \%$ no, $51.8 \%$ to some extent, $33.5 \%$ yes. Next, question 4 , part $2-$ Do you know the safety procedures in the event of a road tunnel fire?-was answered as follows: $26.8 \%$ no, $43.2 \%$ to some extent, $30.0 \%$ yes. The results of part 3 of the survey indicated that the respondents greatly overestimated their knowledge, as $88 \%$ of them did not answer correctly even half the questions (Figure 2). Only $25 \%$ of the respondents answered all the 3 questions correctly in part 4 (Figure 3). When this is compared with the respondents statements, then it is reasonable to conclude that the respondents not only overestimated their knowledge, but also lacked it.

It is presumed that the threat level is perceived as lower than it actually is, which is why we tested the third hypothesis:

Hypothesis 3 (H3). majority of the surveyed participants tend to incorrectly perceive the threat level in an unfavorable scenarios in road tunnels.

The hypothesis is corroborated by the answers given by $41.8 \%$ of the respondents as regards stopping the vehicle in the situation described in question 2, part 4 of the survey. By selecting options related to stopping the vehicle during a fire, the respondents probably perceived the threat level as lower than it really was, putting themselves in grave danger. For example, the investigation into the Gotthard tunnel fire found that the victims had been trapped in smoke within 6 to $7 \mathrm{~min}$ from the start of the fire and were already dead several minutes later (12-15 min from the start of the fire) [4]. In the situation presented in question 2, the localization of the fire (behind the car) and the conditions in the tunnel (visibility) were good enough to allow leaving the tunnel using the vehicle, which should be done without any delay to avoid tragic consequences.

During a tailback in the tunnel (question 8, part 3) almost $70 \%$ of the respondents were unaware of the necessity of turning on the hazard warning lights. The proposed hypothesis is also confirmed by the fact that $43.4 \%$ of the respondents selected answer (b) - go to the nearest emergency exit-when answering question 11 in part 3 of the survey.

The answers given to question 7 , part 3 of the survey are also noteworthy. The large majority $(83.7 \%)$ of the respondents were unaware of the risks posed by a road tunnel fire. In the event of an emergency requiring them to leave their vehicles, these people would spend some time to find and take their documents, fire extinguishers, first-aid kits, water, etc. It can be assumed that they were unaware of the extremely dangerous conditions that may exist during a fire. This behavior is comparable to that of the people involved in the Mont Blanc tunnel fire in 1999. After the fire was extinguished, drivers and passengers of vehicles blocked by the truck that had caught fire were found dead in their cars or right next to them [4]. This demonstrates that they either stayed in their vehicles not attempting any evacuation, or perhaps tried to save their possessions, thus losing precious time. One thing is certain-they were unaware of the danger posed by a tunnel fire.

\subsection{The Role of Experience}

The influence of experience on the level of knowledge of road tunnel safety was studied by comparing the results of the survey between the individuals with experience related to evacuation in various situations-whether during an actual incident in a road tunnel, an actual incident in a different type of structure, evacuation exercises in a road tunnel, or evacuation exercises in a different type of structure, and among respondents with no evacuation experience. We tested the following hypothesis number four:

Hypothesis 4 (H4). Individuals who have participated in an evacuation have better knowledge, allowing them to correctly assess the possible threats in the tunnel and apply the correct rules of road tunnel safety procedures than people with no such experience. 
We found that $38.4 \%$ of the respondents had no evacuation experience, $0.4 \%$ had been involved in an actual incident in a road tunnel, $12.7 \%$ had participated in evacuation exercises in a road tunnel (the evacuation experiment in Laliki or Gdańsk), 8.2\% had been involved in an actual incident in a different type of structure, and $52.5 \%$ had participated in evacuation exercises in a different type of structure.

In order to compare knowledge (measured on the ordinal scale) between two independent groups of respondents (including individuals with and without evacuation experience), we used the Mann-Whitney $U$ test. The test results $(p=0.0015)$, with a significance level of $\alpha=0.05$, point to a statistically significant difference in the level of knowledge between the individuals who had some evacuation experience $(\mathrm{Me}=6, \mathrm{M}=5.61)$ and those who had not been involved in such situations ( $M e=5, M=4.83)$. This shows the positive impact of having experience in any type of evacuation situation on the level of knowledge of road tunnel safety procedures-Figure 7 and Table 2.

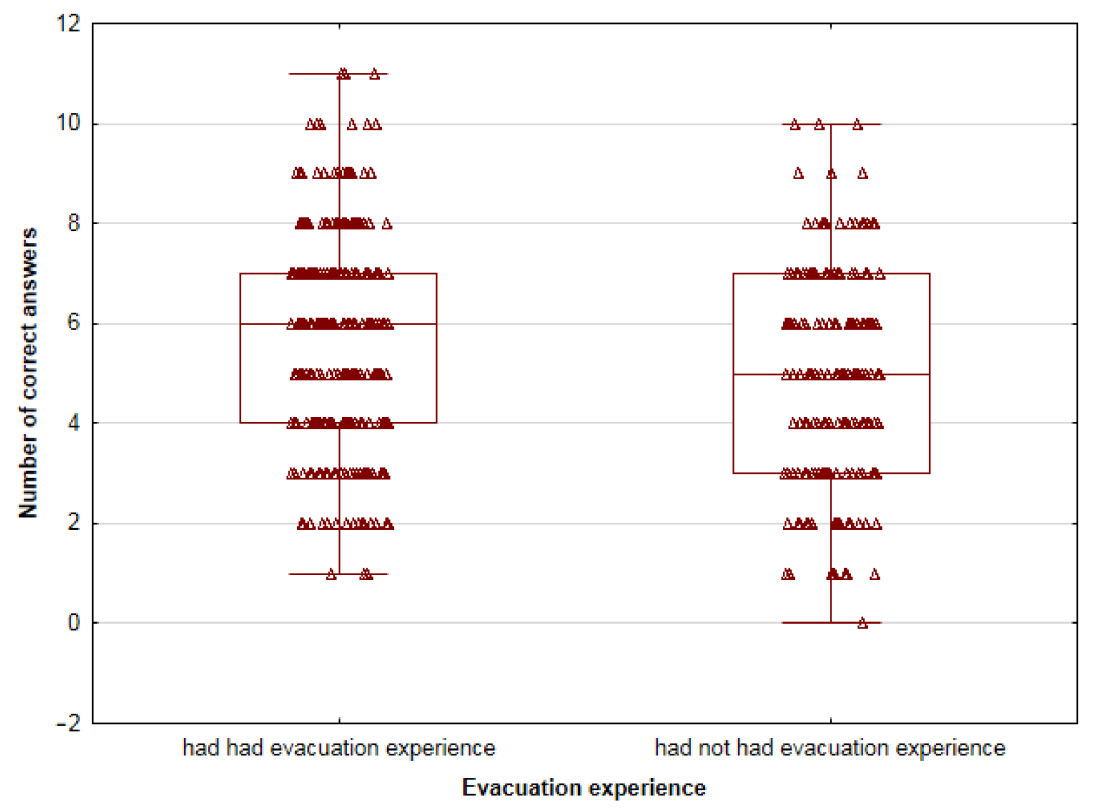

Figure 7. Knowledge of road tunnel safety procedures among the respondents who had evacuation experience and those who had no such experience.

We also analyzed the impact of experience in evacuation on the level of knowledge of tunnel safety procedures. The result of the Kruskal-Wallis test with $p=0.0001$, which was lower than the standard 0.05, demonstrates that the results in each of the groups are not the same, and that in at least one group the results are different than in the other groups. Based on post hoc tests, we identified statistically significant differences between the groups with different experience (part 2, question 6) - namely, the group who had participated in evacuation exercises (evacuation experiment) in a road tunnel (answer c) and the group without any experience in evacuation (answer e), $(p=0.0001)$, and between those who had participated in evacuation exercises in a road tunnel (answer c) and also those who had taken part in actual incident in a different type of structure $(p=0.0033)$ (see Table 3$)$.

On average, participants in the road tunnel evacuation experiment gave the most recommended answers to $M=6.6$ questions in the survey $(\mathrm{Me}=7)$; participants in evacuation exercises in a different type of structure gave the most recommended answers to $M=5.76$ $(\mathrm{Me}=6)$ questions; and respondents with no previous experience in evacuation had on average $\mathrm{M}=5.08$ the most recommended answers $(\mathrm{Me}=5)$. Individuals with experience related to evacuation during an actual incident in a different type of structure gave the most recommended answers to $\mathrm{M}=4.64$ questions $(\mathrm{Me}=4.5)$. 


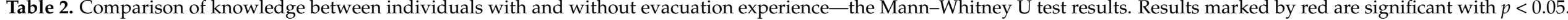

\begin{tabular}{|c|c|c|c|c|c|c|c|c|}
\hline $\begin{array}{l}\text { Sum of Rank "Had Had } \\
\text { Evacuation Experience" }\end{array}$ & $\begin{array}{l}\text { Sum of Rank "Had not Had } \\
\text { Evacuation Experience" }\end{array}$ & $\mathbf{U}$ & $\mathbf{Z}$ & $p$ & $\begin{array}{l}\mathrm{Z} \text { with Continuity } \\
\text { Correction }\end{array}$ & $p$ & $\begin{array}{l}\mathrm{N} \text { "Had Had Evacuation } \\
\text { Experience" }\end{array}$ & $\begin{array}{l}\mathrm{N} \text { "Had not Had } \\
\text { Evacuation Experience" }\end{array}$ \\
\hline $83,580.50$ & $43,679.50$ & $24,958.50$ & 3.18 & 0.00 & 3.21 & 0.00 & 311 & 193 \\
\hline
\end{tabular}

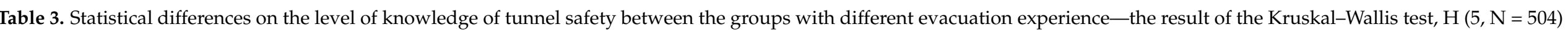
$=27.11625 p=0.0001$.

\begin{tabular}{|c|c|c|c|c|c|}
\hline & $\begin{array}{l}\text { Evacuation Exercises in } \\
\text { a Road Tunnel R:324.54 }\end{array}$ & $\begin{array}{l}\text { Actual Incident in a Tunnel } \\
\text { R:286.5 }\end{array}$ & $\begin{array}{l}\text { Actual Incident in a Different } \\
\text { Type of Structure R:188.05 }\end{array}$ & $\begin{array}{c}\text { Evacuation Exercises in a Different } \\
\text { type of Structure R:263.87 }\end{array}$ & $\begin{array}{c}\text { No Evacuation } \\
\text { Experience R:224.27 }\end{array}$ \\
\hline $\begin{array}{l}\text { Evacuation exercises in a } \\
\text { road tunnel }\end{array}$ & & 1.0000 & 0.0033 & 0.1001 & 0.0001 \\
\hline Actual incident in a tunnel & 1.0000 & & 1.0000 & 1.0000 & 1.0000 \\
\hline $\begin{array}{c}\text { Actual incident in a } \\
\text { different type of structure }\end{array}$ & 0.0033 & 1.0000 & & 0.3017 & 1.0000 \\
\hline $\begin{array}{l}\text { Evacuation exercises in a } \\
\text { different type of structure }\end{array}$ & 0.1001 & 1.0000 & 0.3017 & & 0.0942 \\
\hline No evacuation experience & 0.0001 & 1.0000 & 1.0000 & 0.0942 & \\
\hline
\end{tabular}


Therefore, people who had participated in the evacuation experiment or in evacuation exercises in a different type of structure had higher levels of knowledge than those who had not participated in any evacuation. Furthermore, the respondents who had participated in a road tunnel evacuation experiment had a higher level of knowledge than those who had been involved in evacuation during an actual incident in a different type of structureFigure 8.

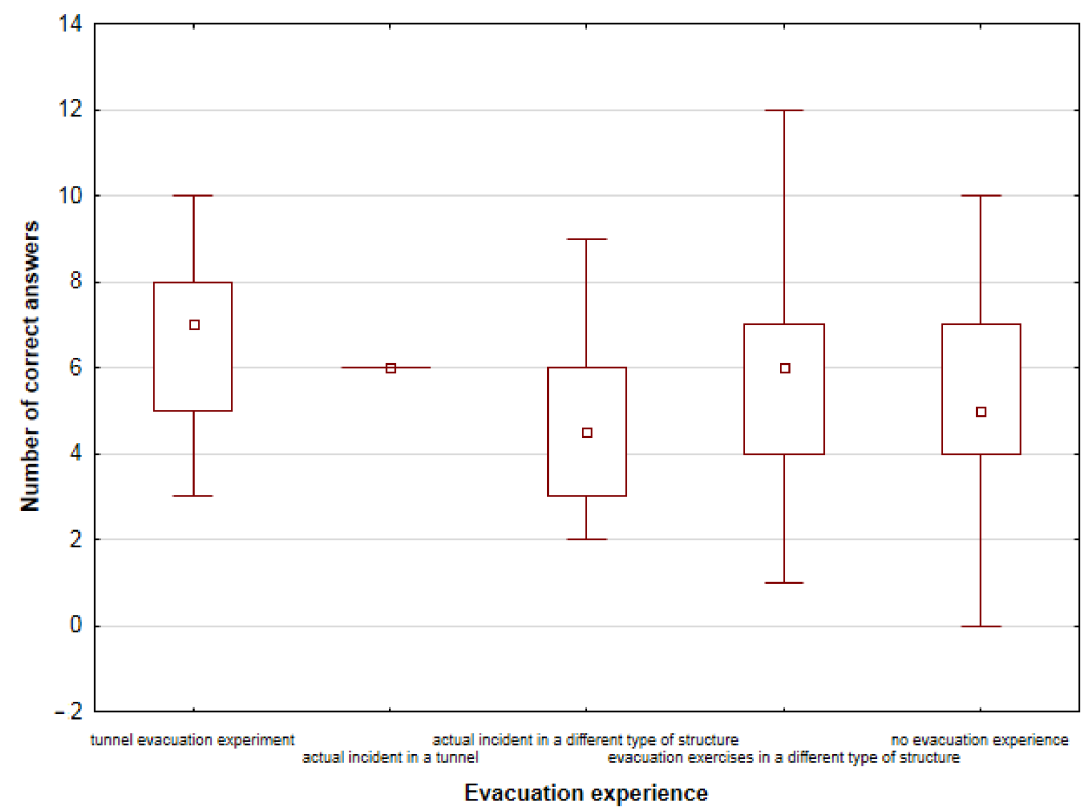

Figure 8. Knowledge of road tunnel safety procedures among the respondents who had experience related to evacuation in various situations.

The group of respondents who had been involved in an actual incident in a road tunnel were excluded from further comparative analysis due to their sample being too small.

There was no statistically significant correlation between respondent's knowledge of the rules of safe road tunnel use and the age of respondents $(p=0.22)$, time of holding a driving license $(p=0.79)$, education $(p=0.62)$, place of residence $(p=0.84)$ or frequency of using road tunnels $(p=0.39)$. It was noted, however, that the average score for men was one point higher than that for women $(p=0.0087)$, which means that, on average, men answered one more question correctly than women.

\subsection{Limitations}

It is important to take into account the impact of the environmental conditions in which the survey was completed on the survey results. The survey was conducted in closed, safe rooms, in a comfortable sitting position, and in silence, which is why it should be assumed that some decisions (answers) may be a case of wishful thinking. The conditions during an actual road tunnel fire, such as the accumulation of smoke, limited visibility, loud fire alarm and voice announcements, and flashing emergency lights, can cause fear and uncertainty, which in turn can affect the decision-making process during evacuation. Furthermore, social influence, which is important in the evacuation process, could not be taken into consideration. It should be emphasized that despite the indicated imperfections, this type of approach is the only way to cover a larger number of road users, and is widely used in safety research $[15,21,22,29]$.

\section{Summary}

This paper presents an assessment of road tunnel safety issues among potential users of road tunnels. We recruited a group of respondents to study their knowledge of 
evacuation procedures and safety issues in road tunnels. The essential hypothesis of this study is that respondents' knowledge of road tunnel safety procedures is not satisfactory. On average, the respondents selected the most recommended answers for only 5.35 out of 15 questions-Figure 1 . None of the respondents showed a comprehensive knowledge of the rules of tunnel safety procedures (part 3); the best result was 9 the most recommended answers to 12 questions. All threats in the tunnel, as presented in part 4, were identified correctly by $25 \%$ of the respondents-Figure 3 .

It was interesting to observe that most of the respondents were convinced that they had a better knowledge of road tunnel safety procedures than was actually the case (Hypothesis 2). Only $14.7 \%$ of the respondents admitted to having no knowledge of road tunnel safety procedures, and $26.8 \%$ to being unaware of the safe procedures in the event of a fire. Furthermore, the respondents tended to incorrectly perceive the threat level in an unfavorable scenario (Hypothesis 3).

The conducted surveys made it possible for us to observe a number of interesting correlations. On the basis of the responses to questions 1 and 10 in part 3 of the survey, we can observe a gap in the knowledge about tunnel infrastructure. It should be clearly emphasized that, in road tunnels, cycling, walking, and parking cars, which create potentially hazardous situations, are forbidden (question 1, part 3 of the survey). Furthermore, turning the car round or reversing in road tunnels are also prohibited. This research indicates a lack of knowledge about these rules (question 2, part 3 of the survey), which is similar to the findings from a previous study [35]. These results could also mean that the respondents feel no difference between a road tunnel and an open road [21].

In critical situations, like a fire in a road tunnel, immediate, efficient, evacuation is the most important issue in the protection of human health and life. Past studies on this topic have shown that tunnel users do not want to leave their personal property behind [35,39]. Almost $84 \%$ of respondents would take personal belongings with them during an evacuation (question 7 in 3 part of the survey), which is similar to results from previous experiments [21,40]. Wasting time in saving material goods during such a dangerous situation can lead to tragic consequences [37]. The most recent example of the significance of this issue was the plane crash at a Russian airport in May 2019, when some of the passengers tried to rescue their belongings, which delayed the evacuation and cost 41 people their lives [41].

These findings are proof that there is a need to clearly emphasize that during an evacuation in the event of a fire in the tunnel, people should save their health and life, rather than material goods. This information can be clearly given through audio instructions, a significant source of information about what to do in critical situations in road tunnels $[8,23]$. This research also shows that behavioral training is very important, because almost $35 \%$ of participants took decisions about evacuation on the basis of how others behaved. Social influence is particularly important during evacuations in road tunnels [33].Some of the survey answers (actions during evacuation) were compared to an experiment in the Emilia Tunnel in Laliki [17]. For instance, in question 11 part 3 and question 1 part 4, some respondents said that in the event of a fire they would go to the nearest emergency exit. The same behavior was observed during the in the last part of the experiment in Laliki. The answers to the survey were given because of lack of knowledge, whereas the actions in the experiment were taken because of social influences, which are the basis of herd behavior, for instance in exit choice during evacuations [22]. Participants in part three of the experiment chose the nearest emergency exit, but in a direction away from the source of the fire. In part 4 of the experiment, where visibility was very poor, the majority of participants lost their orientation, and they made decisions about evacuation on the basis of the actions of others. In a real fire, this behavior can put evacuees at risk. Tunnel users should go in the direction away from the source of fire, avoiding the smoke. The behavior indicated in question 3 part 4 (running to leave the area as quickly as possible) was also observed during the experiment in Laliki-Figure 5-which can pose a risk to human health or life, especially in the event of substantial smoke accumulation. In the same 
question in the survey, $72 \%$ of respondents gave the most recommended answer, which was to move as close to the ground as possible. In the evacuation experiment in Laliki, in part 4, with substantial smoke, none of the participants moved close to the ground, despite the fact that, before that part, they had received tunnel safety instructions with the instruction: In the event of dense smoke, move close to the ground [18]. We doubt that paper instructions fulfill their educational function. Experience in evacuation has a positive impact on the level of knowledge of road tunnel safety. Individuals who have participated in some evacuation have better knowledge of tunnel safety than those without any such experience (Hypothesis 4)-Figure 7. Furthermore, the results of the survey demonstrate a significant educational role of evacuation exercises, especially those conducted in road tunnels-Figure 8. A significant statistical difference was proven in the level of knowledge between road tunnel evacuation experiment participants and the respondents who had been involved in an actual incident in a different type of structure, as well as those with no previous evacuation experience. Therefore, it seems reasonable to conclude that realscale evacuation exercises influence the knowledge of potential tunnel users, which can translate into improved safety in such structures. This is also confirmed by the comments of participants in real-scale evacuation experiments. In the evacuation experiment in the Emilia tunnel in Laliki, after each of the four tests, the participants were asked about the usefulness of the experience gained in the previous exercises and the instructions on safety procedures in the event of a road tunnel fire. As expected, experience in experiments was rated as more useful than safety instructions, including rules, which is consistent with the findings of the experiment described in [20]. Experience from previous experiments was very helpful for $83 \%$ of our participants [17].

We have also observed that people with experience in evacuation exercises conducted in road tunnels were able to better assess the threats in the tunnel than people with other types of evacuation experience or those without any such experience. An awareness of threats and appropriate responses to them can have a positive impact on facilitating the evacuation process by reducing the time needed to respond and to make a decision to evacuate.

It is important to emphasize that people made their decisions on the basis of the behavior of others, so even a little improvement in road tunnel users' knowledge might greatly enhance safety levels in road tunnels.

A significant role of education is to promote and inculcate only those rules and behavior which reduce the risk of harmful and tragic consequences to human health and life (questions 11, 12, part 3). This can be achieved through informational campaigns, based on evidence informed by this kind of research, which should cover correct safety behavior according to Directive 2004 [14]. In accordance with this regulation, informational campaigns should also describe the appropriate behavior during everyday tunnel use, congestion, and accidents. Furthermore, comprehensive safety rules should be provided. While respondents might have known individual safety rules, we observed a lack of a comprehensive approach, which might been caused by insufficient awareness of threats (questions 6, 8, 9, part 3). In order to design informational campaigns well, it is crucial to identify potential users' knowledge of safety rules in road tunnels. The aspects highlighted in this paper should be taken into consideration in informational campaigns.

We believe that, as part of any future research, more evacuation experiments should be carried out to confirm whether in real conditions people behave as they stated in this survey. Verification of these results can be also done by analyzing the videos from monitoring systems in control centers, and interviewing road tunnel operators. Further work is also required to better comprehend human behavior in road tunnel infrastructure.

Author Contributions: Conceptualization, N.S.-P., J.W. and J.P.; methodology, N.S.-P., J.W. and J.P.; formal analysis, N.S.-P., J.W. and J.P.; writing-original draft preparation, N.S.-P., J.W. writingreview and editing, N.S.-P., J.W. visualization, N.S.-P., supervision, N.S.-P. All authors have read and agreed to the published version of the manuscript. 
Funding: This research received no external funding.

Institutional Review Board Statement: Ethical review and approval were waived for this study, due to the reason that survey research methodology was used and datasets were all anonymized and do not contain personal, identifiable data. The project raises no significant ethical issues.

Informed Consent Statement: Informed consent was obtained from all subjects involved in the study.

Data Availability Statement: The data presented in this study are available on request from the corresponding author.

Conflicts of Interest: The authors declare no conflict of interest.

\section{Appendix A}

Survey (with authors' comments)

\section{Appendix A.1. Part 1}

This survey has been designed to test knowledge of the rules of road tunnel safety procedures in various situations and incidents. While completing this survey, follow the order of the questions and do not return to previously answered questions. Complete the survey unaided, do not use other sources.

I. Age:

II. Gender:
(a) female,
(b) male.

III. Education:
(a) primary,
(b) lower-secondary,
(c) vocational,
(d) upper-secondary,
(e) higher.

IV. Profession or study program:

V. Place of residence:
(a) rural area,
(b) city with a population of up to 50,000 ,
(c) city with a population of 50,000 to 100,000 ,
(d) city with a population of 100,000 to 500,000 ,
(e) city with a population of more than 500,000,

VI. Driving license:
(a) yes-how long:
(b) no.

Appendix A.2. Part 2

I. How often do you use road tunnels?
(a) never,
(b) once to several times a year,
(c) a dozen or so times a year,
(d) several dozen times a year,
(e) once a week,
(f) at least twice a week.

II. How long are the tunnels that you use? (select all answers that apply to you):
(a) $\quad 100-200 \mathrm{~m}$,
(b) 200-500 m,
(c) $500-1000 \mathrm{~m}$, 
(d) $\quad 1000-3000 \mathrm{~m}$,

(e) more than $3000 \mathrm{~m}$.

III. Do you know the rules of safe road tunnel use?

(a) yes,

(b) no,

(c) to some extent.

IV. Do you know the safety procedures in the event of a road tunnel fire?
(a) yes,
(b) no,
(c) to some extent.

V. Have you ever evacuated from a road tunnel during an actual incident?
(a) yes
(b) no.

VI. Have you ever been involved in any evacuation? (select all answers that apply to you)
(a) yes-during an actual incident in a road tunnel,
(b) yes-during an actual incident in a different type of structure,
(c) yes-during evacuation exercises in a road tunnel,
(d) yes-during evacuation exercises in a different type of structure,
(e) no.

Appendix A.3. Part 3-Questions on Safety Rules-Multiple-Choice Questions

1. A road tunnel can consist of:
(a) space for cars to move,
(b) a parallel evacuation tunnel for pedestrian evacuation
(c) emergency exits,
(d) two spaces for car traffic, each in the opposite direction,
(e) a cycling path,
(f) emergency bays,
(g) a car park.

Comment: In this case, we checked knowledge about tunnel infrastructure.

2. In a road tunnel it is strictly prohibited to:
(a) turn the car around
(b) use hazard warning lights
(c) reverse
(d) brake suddenly
(e) use the horn
(f) stop without a legitimate reason
(g) none of the above

Comment: We pointed out different behaviors of drivers, some of them are risky; however safety instructions indicate directly avoiding turning the car around, reversing, or stopping without a legitimate reason as the most recommended answers.

3. What to do before entering a road tunnel:
(a) take your sunglasses off,
(b) make sure that dipped beam headlights are turned on,
(c) turn on main beam headlights,
(d) turn off the radio,
(e) turn on the radio,
(f) close the windows,
(g) turn on hazard warning lights, 
(h) none of the above.

Comment: In this case, we referred to the safety procedures recommended in a normal situation, before entering a tunnel.

4. When using a road tunnel, you should:

(a) maintain a safe distance from the car in front,

(b) not exceed the speed limit,

(c) turn off the air-conditioning,

(d) give priority to the signs displayed on the boards,

(e) none of the above.

Comment: The safety instructions indicate that during normal operation one should maintain the safety rules (keep a safe distance from the car in front, not exceed the speed limit, give priority to the signs displayed on the boards).

5. When should you leave the car in a tunnel:

(a) never,

(b) always in the event of a tunnel fire,

(c) always in the event of a tunnel fire if there is no option to drive out of the tunnel,

(d) always if it is necessary to stop the vehicle, e.g., due to a tailback,

(e) always if another car breaks down,

(f) none of the above.

Comment: According to safety instructions, it is prohibited to stop the car without a legitimate reason. The same applies to about leaving the car. One should always leave the cars in the event of a tunnel fire if there is no option to drive out of the tunnel.

6. If it is necessary to stop the vehicle (in a two-way tunnel):

(a) park as close as possible to the right wall of the tunnel,

(b) park as close to the right edge of the road as possible (no bay),

(c) park as close to the left edge of the road as possible,

(d) park in an emergency bay,

(e) park the car where you are,

(f) none of the above.

Comment: In this case, we asked about the course of action when it is necessary to stop the car in a two-way tunnel. According to the safety instructions, it is recommended to park as close as possible to the right edge of the road or park in an emergency bay.

7. What do you take with you if you suddenly have to leave your car in the tunnel (because of a fire)?
(a) documents,
(b) most valuable items,
(c) as much as you can carry,
(d) car keys,
(e) first-aid kit,
(f) fire extinguisher from the car,
(g) water,
(h) none of the above.

Comment: In this case, we checked the awareness of threats in such critical conditions as a fire. Safety instructions recommend in that case to start evacuation immediately. The time needed to find and take the intended item is likely to extend the time required to start evacuation.

8. In the case of a tailback in a two-way road tunnel, you should:
(a) maintain a safe distance from the car in front,
(b) turn on main beam headlights,
(c) adhere to the signs displayed on the boards,
(d) overtake if needed, 
(e) turn on hazard warning lights,

(f) turn off the air-conditioning,

(g) turn off the radio,

(h) turn on the radio,

(i) listen to information broadcast in the tunnel,

(j) turn off the engine after stopping the vehicle,

(k) none of the above.

Comment: In this case we checked knowledge of the safety procedures in the case of a tailback. According to the safety instructions it is strongly recommended maintain a safe distance from the car in front, adhere to the signs displayed on the boards and turn on hazard warning lights. It is also recommended to turn on the radio to listen to information broadcast in the tunnel, and turn off the engine after stopping the vehicle.

9. If your car is involved in a collision in a road tunnel you should:

(a) turn on hazard warning lights,

(b) place a warning triangle,

(c) adhere to the signs displayed on the boards,

(d) park as close to the right edge of the road as possible (no bay),

(e) park as close to the left edge of the road as possible,

(f) turn off the engine,

(g) call for help,

(h) none of the above.

Comment: In this case, according to the existing safety instructions, we checked knowledge of safety procedures in the case of collision. The question aims to point out answers that minimize the risks for a potential user.

10. In the event of a road tunnel fire, which systems do you expect will be activated?
(a) fire alarm,
(b) voice announcements informing about the fire and the necessity of leaving the tunnel,
(c) ultraviolet lamps,
(d) emergency lights,
(e) ventilation,
(f) air-conditioning,
(g) none of the above.

Comment: In this case, we checked the fire infrastructure in a tunnel.

11. In the event of a collision and vehicles being on fire in front of you and substantial smoke accumulation in the road tunnel, and the fire alarm being triggered, you should:
(a) go to the emergency exit, avoiding the smoke,
(b) go to the nearest emergency exit,
(c) place a warning triangle,
(d) try to extinguish the fire on your own,
(e) remain in the car to not interfere with the operations of the fire service,
(f) use the emergency cabinet to call for help,
(g) hide in a niche in the tunnel,
(h) none of the above.

Comment: Safety instructions recommend in case of fire with substantial smoke accumulation to leave the vehicle immediately and next to leave the tunnel through the emergency exit, avoiding smoke.

12. If it is necessary to leave the car in a road tunnel due to a vehicle in front of you being on fire, you should:

(a) close the car and take the keys, 
(b) leave the car open and take the key,

(c) leave the car open and the key in the ignition,

(d) none of the above.

Comment: In this case, according to the existing safety instructions, it is recommended to leave the car open and the key in the ignition in order to facilitate rescue operations for the relevant services.

\section{Appendix A.4. Part 4-Situations in a Road Tunnel-Single-Choice Questions}

1. In a 7-km-long road tunnel, there is a fire right in front of the coach you are in. The coach stops between the two emergency exits leading to the evacuation tunnel. The distance to the emergency exit located towards the truck on fire is $50 \mathrm{~m}$, and $150 \mathrm{~m}$ to the emergency exit in the opposite direction. The accumulation of smoke in the tunnel is substantial. Voice announcements and fire alarm start, emergency lights are turned on. After a moment, almost the entire truck is on fire. What do you do?

(a) Stay in the vehicle and wait for the rescue services to arrive.

(b) Leave the vehicle as you fear it might catch fire, and wait in the tunnel for the rescue services to arrive.

(c) Try to extinguish the fire.

(d) Go to the nearest emergency exit and leave the tunnel.

(e) Go to a farther emergency exit $150 \mathrm{~m}$ from your location and leave the tunnel.

(f) Leave the tunnel by walking the main bay towards the fire.

(g) Leave the tunnel by walking the main bay in the direction opposite to the fire.

(h) Other actions:

Comment: The existing safety instructions in Poland and many other countries recommend in this case to leave the vehicle immediately and next to leave the tunnel through the emergency exit, avoiding smoke. The question aims to indicate answers aimed at global minimizing of the risk in case of fire for a statistical user.

2. You are driving a car with your family in Switzerland. As you are passing through one of the tunnels, fire breaks up behind your car. A small amount of smoke is accumulating in the tunnel. What do you do?

(a) Park the vehicle as close to the right edge of the road as possible, turn off the engine, stay with the family in the vehicle and wait for the rescue services to arrive.

(b) Stop the car and call for help.

(c) Stop the car, turn off the engine and go to the nearest emergency exit.

(d) Continue to drive out of the tunnel.

(e) Leave the vehicle as you fear it might catch fire, and wait for the rescue services to arrive.

(f) Other actions:

Comment: According to the safety instructions, it is most recommended to drive out of the tunnel, if it is possible (and next, to notify the appropriate emergency services).

3. You are traveling with your friends to France by coach on a sightseeing tour. In a one-way 10-km-long road tunnel, a fire broke out right in front of the coach you are in. The coach stops in the tunnel. After a while, there is a lot of smoke in the tunnel. What do you do after leaving the vehicle when it turns out that visibility in the tunnel is very poor (and thus the distance to emergency exits is unknown)?

(a) Go back to the vehicle and remain inside until the rescue services to arrive.

(b) Stop and talk with other people to determine the evacuation route together.

(c) Leave the vehicle as you fear it might catch fire, and wait for the rescue services to arrive.

(d) Move as close to the ground as possible, and head to the emergency exit in the direction opposite to the fire. 
(e) Move as close to the ground as possible, and head to the emergency exit towards the fire.

(f) Run to leave the area as quickly as possible, heading to the emergency exit towards the fire.

(g) Run to leave the area as quickly as possible, heading to the emergency exit in the direction opposite to the fire.

(h) Other actions:

Comment: In this case, the safety instructions indicate that toxic smoke is a significant hazard, therefore it is recommended to avoid smoke and keep away from the fire.

\section{Appendix B}

\section{Appendix B.1. Knowledge of Road Tunnel Safety Procedures}

We analyzed the answers to each question in part 3 of the survey. These constituted an important component influencing the outcome of the assessment of the respondents' knowledge of the road tunnel safety rules.

Some respondents, when asked about tunnel infrastructure (question 1), expected a cycling path (14.5\% of answers) or a car park $(4.2 \%)$, while it is generally prohibited to ride bicycles in road tunnels and stop vehicles without a legitimate reason. Question 1 was answered correctly by $28 \%$ of the respondents, who selected the options a, b, c, d, and $\mathrm{f}$. The answers given to question 1 in part 4 of the survey are presented in Figure A1a. The answers marked in green are the most proper in the context of risk minimization and recommended procedures. This convention is used for all the questions.

In question 2, the respondents were asked to indicate the activities which are strictly prohibited in a road tunnel. For this question, $18.9 \%$ of the respondents were positive that it is prohibited to use the horn or hazard warning lights $(1.8 \%)$ when driving in a tunnel. The correct answers were given by $36 \%$ of the respondents, who selected the options a, c, and $\mathrm{f}$-Figure A1b.

As regards question 3, concerning what to do before entering a road tunnel, only $1.4 \%$ of the respondents selected all the most recommended options: $a, b$, and e-Figure A1c. It is also alarming that only $5.6 \%$ of the respondents would turn on a radio before entering the tunnel to hear the voice announcements made by the management center on a dedicated frequency.

The next question concerned the use of road tunnels in normal conditions. The answers showed that $94.2 \%$ of the respondents would maintain a safe distance from the vehicle in front, $89.6 \%$ would not exceed the speed limit, and $84.8 \%$ would adhere to the instructions displayed on the boards. We found that $75 \%$ of the respondents answered this question with the most recommended answers $(a, b, d)$. All answers given to question 4 in part 3 of the survey are presented in Figure A1d.

In question 5, we asked the respondents about situations in which they should leave the car in a tunnel in the event of a tunnel fire. The most recommended answer-always if there is no option to drive out of the tunnel-was indicated by $68.1 \%$ of the respondentsFigure A1e. We found that $19.5 \%$ would leave their cars regardless of the location of the threat. If the fire is located behind our vehicle and visibility is good enough to continue driving, we should exit the tunnel by driving out of it.

Question 6 required the respondents to state the course of action when it is necessary to stop the car in a two-way tunnel. We found that $27.2 \%$ of the respondents answered this question with the most recommended answers, by selecting options $b$ ) park as close to the right edge of the road as possible (no bay) and d) park in an emergency bay-Figure A1f. However, $43 \%$ of the respondents would park as close as possible to the right wall of the tunnel, blocking the pavement intended for pedestrian evacuation.

Question 7: What do you take with you if you suddenly have to leave your car in the tunnel-was answered as follows: $68.1 \%$ of the respondents would take documents, $38.7 \%$ a first-aid kit, $37.1 \%$ a fire extinguisher, $34.7 \%$ water, $21.8 \%$ car keys, $14.7 \%$ most valuable items and $1.8 \%$ as much as they could carry. The results show that $17.3 \%$ of the respondents 
selected the correct answer: none of the answers is correct; however, ultimately, $16.3 \%$ opted only for this answer, thereby correctly answering the question-Figure A2a.

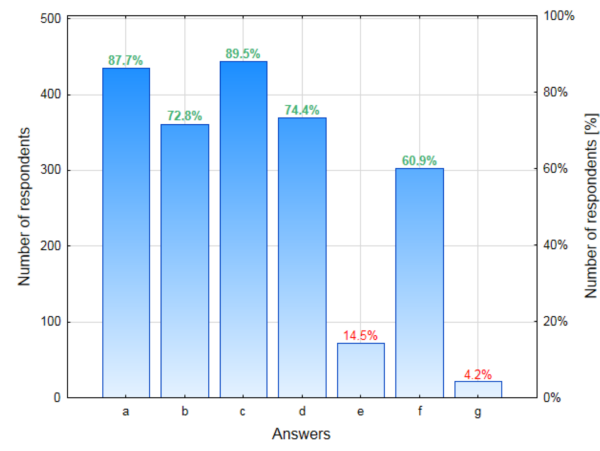

(a) Answers to question 1, part 3

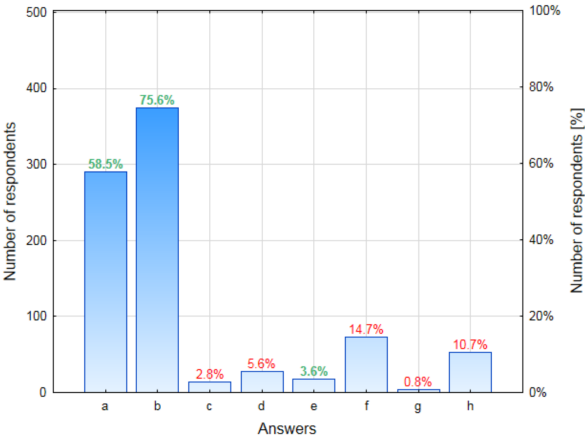

(c) Answers to question 3, part 3

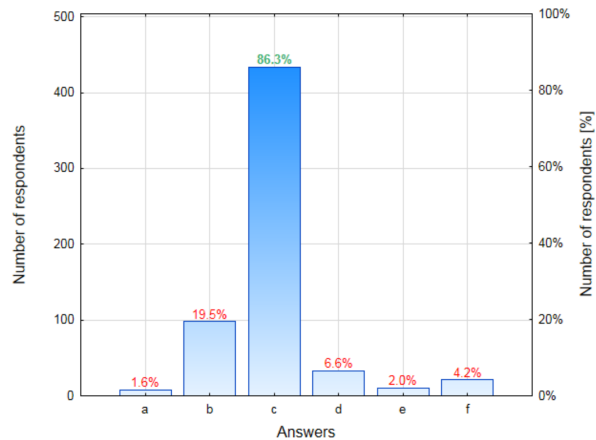

(e) Answers to question 5, part 3

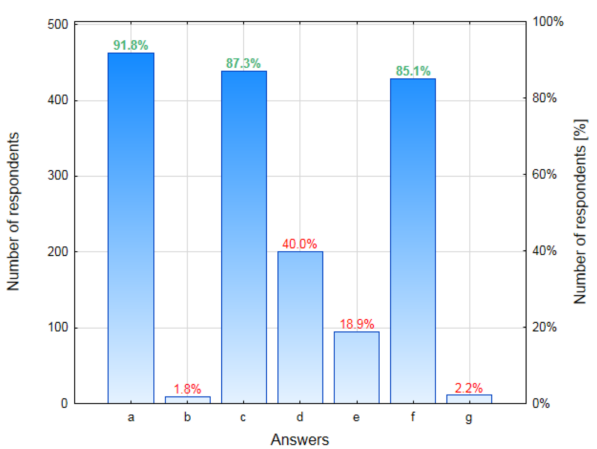

(b) Answers to question 2, part 3

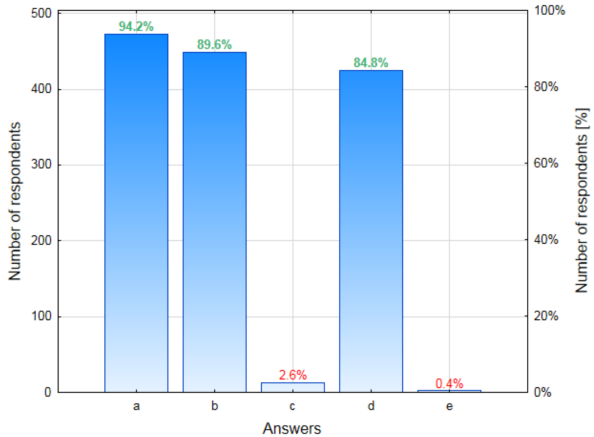

(d) Answers to question 4, part 3

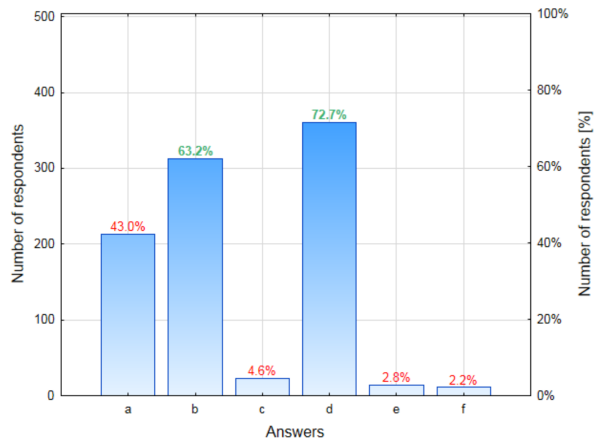

(f) Answers to question 6, part 3

Figure A1. (a-f) Answers to first questions 1-6 from part 3 of the survey. The most recommended answers are marked green, and other answers are marked red.

Only one person answered the next question with the most recommended answers. The question is concerned with behavior during a tailback in a two-way tunnel, by selecting options a, c, e, h, i, and j. In the case of a tailback in a road tunnel, only $30.7 \%$ of the respondents would turn on the hazard warning lights and $44.2 \%$ would stop the vehicle and turn off the engine. The other answers given to question 8 are presented in Figure A2b.

In question 9, the respondents were asked what to do in the event of a collision in a road tunnel. We found that $84 \%$ would turn on the hazard warning lights, $83.4 \%$ would place a warning triangle, $82.8 \%$ would call for help, $74.5 \%$ would turn off the engine, $35.6 \%$ would adhere to the signs displayed on the boards. Unfortunately, only $2.6 \%$ of the respondents would react in this situation in a comprehensive manner, with all the most recommended options selected: a, b, c, f, and g-Figure A2c.

Question 10 concerned fire infrastructure in a tunnel. The respondents were asked to select all the systems which can be activated during a road tunnel fire: $89.8 \%$ selected 
the fire alarm, $85.2 \%$ voice announcements informing about the fire and the necessity of leaving the tunnel, $73.1 \%$ emergency lights, and $49.5 \%$ ventilation-Figure A2d. While the majority of the respondents pointed to the right systems, only $31 \%$ of them gave the most recommended answers (options $\mathrm{a}, \mathrm{b}, \mathrm{d}$, and e).

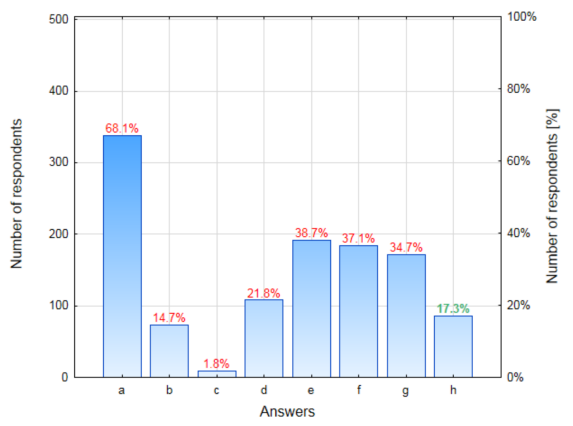

(a) Answers to question 7, part 3

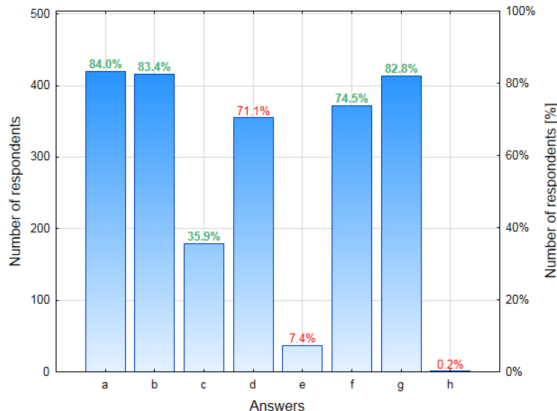

(c) Answers to question 9, part 3

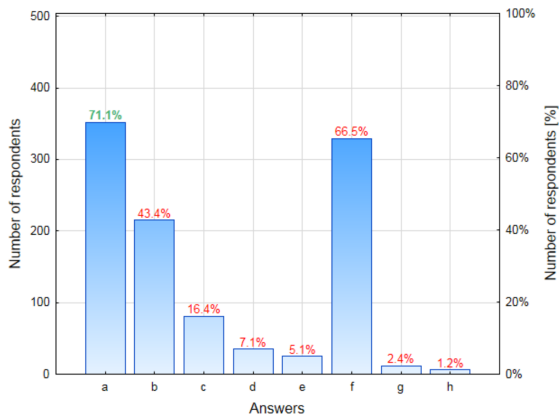

(e) Answers to question 11, part 3

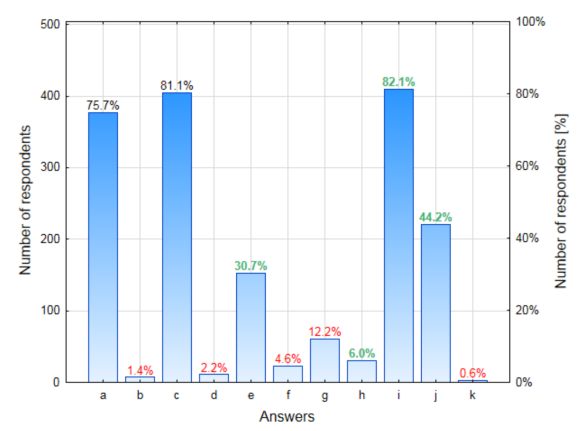

(b) Answers to question 8, part 3

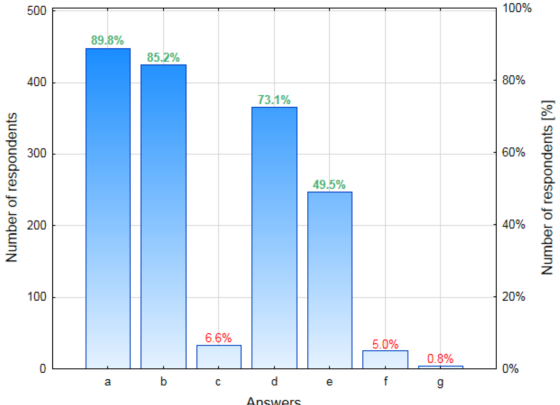

(d) Answers to question 10, part 3

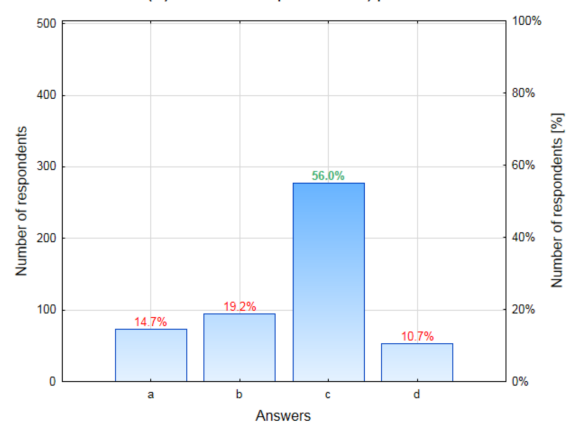

(f) Answers to question 12, part 3

Figure A2. (a-f) Answers to first questions 7-12 from part 3 of the survey. The most recommended answers are marked green, and other answers are marked red.

As regards the next question, i.e., what should be done in the event of a collision and vehicles being on fire in front of you, $14.9 \%$ of the respondents gave the most recommended answers, i.e., they would go to an emergency exit, avoiding the smoke. In the question it was indicated that there was substantial smoke accumulation in the tunnel and that a fire alarm had been triggered. Despite this, $43.4 \%$ of the respondents selected a different answer, indicating that they would go to the nearest emergency exit, which could lead them towards the fire. Such a decision can cause additional threats, often making safe evacuation impossible. The distribution of the answers given to question 11 is presented in Figure A2e.

The last question in the survey concerned a situation where it is necessary to leave the car in a road tunnel due to a vehicle being on fire (see Figure A2f). The respondents were asked what to do in this situation. More than half the respondents (54.6\%) answered this question with the most recommended answers by selecting option c: leave the car open and the key in the ignition. 


\section{Appendix B.2. Assessment of Road Tunnel Threats}

To calculate the sums of the most recommended answers, we individually analyzed each scenario in part 4 of the survey. Question 1 concerned the selection of the emergency exit during a truck fire in a road tunnel (the full text of each question can be found in Appendix A). When asked what to do in such a situation, 55.5\% of the respondents gave the most recommended answers: go to a farther emergency exit $150 \mathrm{~m}$ from your location and leave the tunnel-Figure A3a. The other commonly chosen answer (29\%) was to go to the nearest emergency exit, which can actually put the evacuees' lives at risk. When evacuating, people should avoid the smoke and head in a direction opposite to the source of the fire.

Question 2 concerned a fire occurring behind the car of the potential driver. The respondents were asked to indicate the recommended course of action in this situation, and $47.9 \%$ of them pointed out the most recommended action in response to the critical situation in the tunnel; namely, to continue to drive out of the tunnel-Figure A3b. The light smoke and the location of the fire presented in scenario 2 make it possible for the driver to safely leave the tunnel in his or her own vehicle. However, as many as $22.8 \%$ of the respondents would stop and call out for help, and $14.6 \%$ would stop and go to the nearest emergency exit. Stopping inside the tunnel can pose an additional risk and result in a situation endangering other users or even in a tragedy.

Question 3 was very similar to Question 1, the difference being that question 3 assumed very poor visibility levels and thus an unknown distance to the emergency exits. The respondents were asked what to do after leaving the vehicle. The most recommended answers-move as close to the ground as possible, and head to the emergency exit in a direction opposite to the fire-were selected by $71.9 \%$ of the respondents. On the other hand, $14.2 \%$ of the respondents opted for-run to leave the area as quickly as possible, heading to the emergency exit in a direction opposite to the fire-Figure A3c.

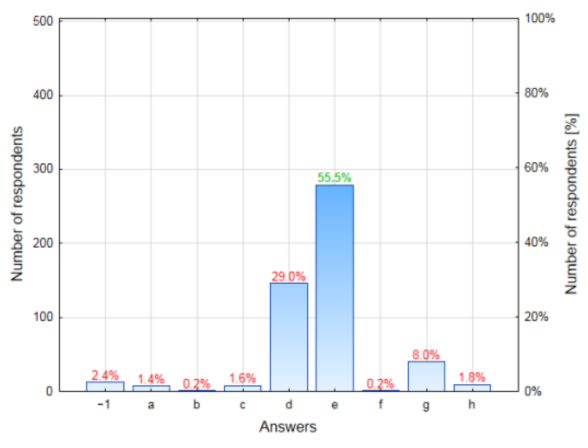

(a) Answers to question 1, part 4

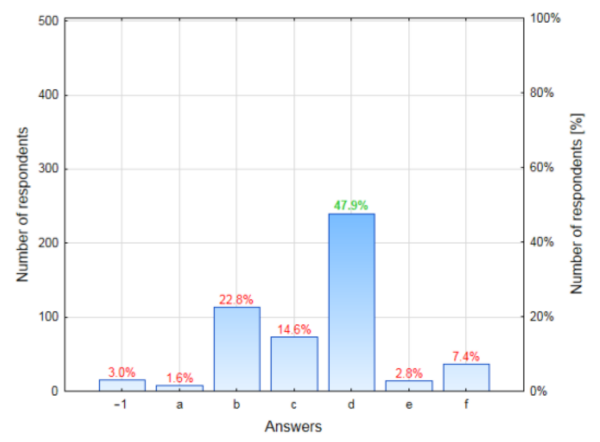

(b) Answers to question 2, part 4

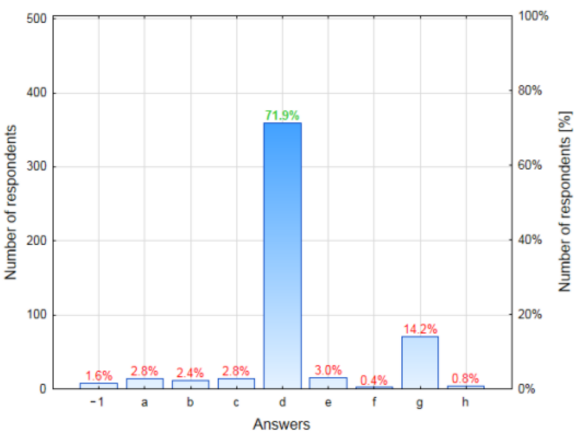

(c) Answers to question 4, part 4

Figure A3. (a-c) Answers to part 4 of the survey. The most recommended answers are marked green, and other answers are marked red. 


\section{References}

1. Caliendo, C.; De Guglielmo, M.L. Accident Rates in Road Tunnels and Social Cost Evaluation. Procedia Soc. Behav. Sci. 2012, 53, 166-177. [CrossRef]

2. Fera, M.; Macchiaroli, R. Use of analytic hierarchy process and fire dynamics simulator to assess the fire protection systems in a tunnel on fire. Int. J. Risk Assess. Manag. 2010, 14, 504-529. [CrossRef]

3. Rudin-Brown, C.M.; Edquist, J.; Lenné, M.G. Effects of driving experience and sensation-seeking on drivers' adaptation to road environment complexity. Saf. Sci. 2014, 62, 121-129. [CrossRef]

4. Voeltzel, A.; Dix, A. A comparative analysis of the mont-blanc, tauern and gothard tunnel fires. Routes/Roads 2004, $324,18-34$.

5. Ronchi, E.; Nilsson, D.; Gwynne, S.M.V. Modelling the impact of emergency exit signs in tunnels. Fire Technol. 2012, 48, 961-988. [CrossRef]

6. Chammem, T.; Vauquelin, O.; Mhiri, H. Performance evaluation of alternative tunnel longitudinal ventilation systems using two inclined jets. Tunn. Undergr. Space Technol. 2014, 41, 53-61. [CrossRef]

7. Mitrovich, S.; Valenti, G.; Mancini, M. A decision support system (dss) for traffic incident management in roadway tunnel infrastructure. In Proceedings of the 34 th European Transport Conference, Strasbourg, France, 25 May 2006.

8. Borghetti, F.; Derudi, M.; Gandini, P.; Frassoldati, A.; Tavelli, S. Safety in Road Tunnels; Springer International Publishing: Cham, Switzerland, 2016; pp. 1-5. [CrossRef]

9. Burns, P.; Stevens, G.; Sandy, K.; Dix, A.; Raphael, B.; Allen, B. Human behaviour during an evacuation scenario in the sydney harbour tunnel. Aust. J. Emerg. Manag. 2013, 28, 20-27.

10. Tomar, M.; Khurana, S.; Singh, R. Behaviour of tunnel lining material in road tunnel fire. IOP Conf. Ser. Mater. Sci. Eng. 2018, 346, 012077. [CrossRef]

11. Borghetti, F.; Cerean, P.; Derudi, M.; Frassoldati, A. Tunnel infrastructure measures, equipment and management procedures. In Road Tunnels; Springer: Cham, Switzerland, 2019; pp. 27-38. [CrossRef]

12. Holický, M.; Diamantidis, D. Optimization of Road Tunnel Safety. Beton Stahlbetonbau 2008, 103, 10-15. [CrossRef]

13. Schlosser, F.; Rázga, M.; Danišovič, P. Risk Analysis in Road Tunnels. Procedia Eng. 2014, 91, 469-474. [CrossRef]

14. European Parliament. Directive 2004/54/EC of the European Parliament and of the Council of 29 April 2004 on Minimum Safety Requirements for Tunnels in the Transeuropean road Network; European Parliament: Brussels, Belgium, 2004.

15. Obregón-Biosca, S.A.; Betanzo-Quezada, E.; Romero-Navarrete, J.A.; Ríos-Nuñez, M. Rating road traffic education. Transp. Res. Part F Traffic Psychol. Behav. 2018, 56, 33-45. [CrossRef]

16. Blanco, C.B.T. Una alternativa para la formación vial. Rev. Educ. 2008, 32, 15. [CrossRef]

17. Porzycki, J.; Schmidt-Polończyk, N.; Wass, J. Pedestrian behavior during evacuation from road tunnel in smoke conditionEmpirical results. PLoS ONE 2018, 13, e0201732. [CrossRef] [PubMed]

18. Safety Rules in a Road Tunnel in Laliki. Available online: https://www.gddkia.gov.pl/pl/aprint/15948/ (accessed on 20 April 2019).

19. Safety Rules in a Road Tunnel in Gdansk. Available online: https://gzdiz.gda.pl/drogi/tunel-pod-martwa-wisla,a,3177 (accessed on 20 April 2019).

20. Kinateder, M.; Pauli, P.; Müller, M.; Krieger, J.; Heimbecher, F.; Rönnau, I.; Bergerhausen, U.; Vollmann, G.; Vogt, P.; Mühlberger, A. Human behaviour in severe tunnel accidents: Effects of information and behavioural training. Transp. Res. Part F Traffic Psychol. Behav. 2013, 17, 20-32. [CrossRef]

21. Kirytopoulos, K.; Kazaras, K.; Papapavlou, P.; Ntzeremes, P.; Tatsiopoulos, I. Exploring driving habits and safety critical behavioural intentions among road tunnel users: A questionnaire survey in Greece. Tunn. Undergr. Space Technol. 2017, 63, 244-251. [CrossRef]

22. Ma, Z.-L.; Shao, C.-F.; Zhang, S.-R. Characteristics of traffic accidents in Chinese freeway tunnels. Tunn. Undergr. Space Technol. 2009, 24, 350-355. [CrossRef]

23. Ronchi, E.; Fridolf, K.; Frantzich, H.; Nilsson, D.; Walter, A.L.; Modig, H. A tunnel evacuation experiment on movement speed and exit choice in smoke. Fire Saf. J. 2018, 97, 126-136. [CrossRef]

24. Bae, S.; Choi, J.-H.; Ryou, H.S. Modification of Interaction Forces between Smoke and Evacuees. Energies 2020, 13, 4177. [CrossRef]

25. Park, Y.; Lee, Y.; Na, J.; Ryou, H.S. Numerical Study on the Effect of Tunnel Aspect Ratio on Evacuation with Unsteady Heat Release Rate Due to Fire in the Case of Two Vehicles. Energies 2019, 12, 133. [CrossRef]

26. Casse, C.; Caroly, S. Analysis of critical incidents in tunnels to improve learning from experience. Saf. Sci. 2019, 116, 222-230. [CrossRef]

27. Xie, B.; Zhang, S.; Xu, Z.; He, L.; Xi, B.; Wang, M. Experimental study on vertical evacuation capacity of evacuation slide in road shield tunnel. Tunn. Undergr. Space Technol. 2020, 97, 103250. [CrossRef]

28. Fridolf, K.; Ronchi, E.; Nilsson, D.; Frantzich, H. The representation of evacuation movement in smoke-filled underground transportation systems. Tunn. Undergr. Space Technol. 2019, 90, 28-41. [CrossRef]

29. Kouabenan, D.; Gandit, C.M.; Caroly, S. Behaviors and causal explanations of road-tunnel users during a fire. Psihol. Resurselor Umane 2011, 9, 69-84. [CrossRef]

30. Kinateder, M.; Müller, M.; Jost, M.; Mühlberger, A.; Pauli, P. Social influence in a virtual tunnel fire-Influence of conflicting information on evacuation behavior. Appl. Ergon. 2014, 45, 1649-1659. [CrossRef] 
31. Porzycki, J.; Wąs, J.; Hedayatifar, L.; Hassanibesheli, F.; Kułakowski, K. Velocity correlations and spatial dependencies be-tween neighbors in a unidirectional flow of pedestrians. Phys. Rev. E 2017, 96, 022307. [CrossRef]

32. Lubaś, R.; Wąs, J.; Porzycki, J. Cellular Automata as the basis of effective and realistic agent-based models of crowd behavior. J. Supercomput. 2016, 72, 2170-2196. [CrossRef]

33. Nilsson, D.; Johansson, M.; Frantzich, H. Evacuation experiment in a road tunnel: A study of human behaviour and technical installations. Fire Saf. J. 2009, 44, 458-468. [CrossRef]

34. Boer, L.C.; Veldhuijzen van Zanten, D.W. Behaviour on tunnel fire. In Pedestrian and Evacuation Dynamics; Waldau, N., Gattermann, P., Knoflacher, H., Schreckenberg, M., Eds.; Springer: Berlin/Heidelberg, 2005; pp. 91-98.

35. Gandit, M.; Kouabenan, D.R.; Caroly, S. Road-tunnel fires: Risk perception and management strategies among users. Saf. Sci. 2009, 47, 105-114. [CrossRef]

36. Yeung, J.S.; Wong, Y.D.; Xu, H. Driver perspectives of open and tunnel expressways. J. Environ. Psychol. 2013, 36, 248-256. [CrossRef]

37. Amundsen, F. Studies of driver behaviour in Norwegian road tunnels. Tunn. Undergr. Space Technol. 1994, 9, 9-15. [CrossRef]

38. Martens, M.; Jenssen, G. Human behaviour in tunnels: What further steps to take? In Proceedings of the Fifth International Symposium on Tunnel Safety and Security (ISTSS 2012), New York, NY, USA, 14-16 March 2012; Ingason, J., Lönnermark, A., Eds.; SP Technical Research Institute of Sweden: New York, NY, USA, 2012; pp. 69-86.

39. Ronchi, E.; Nilsson, D. Fire evacuation in high-rise buildings: A review of human behaviour and modelling research. Fire Sci. Rev. 2013, 2, 7. [CrossRef]

40. Zhang, Y.; Yan, Z.; Zhu, H.; Shen, Y. Fire Response Performance and Social Behavior in Tunnels Distinguishing from Buildings in Evacuation. In Proceedings of the GeoShanghai 2018 International Conference: Tunnelling and Underground Construction, Shanghai, China, 27-30 May 2018; Springer: Singapore, 2018; pp. 625-632. [CrossRef]

41. The Aviation Safety Network. Available online: https://aviation-safety.net/database/record.php?id=20190505-0 (accessed on 20 April 2019). 